NBER WORKING PAPER SERIES

INFLATION'S ROLE IN OPTIMAL MONETARY-FISCAL POLICY

Eric M. Leeper

Xuan Zhou

Working Paper 19686

http://www.nber.org/papers/w19686

NATIONAL BUREAU OF ECONOMIC RESEARCH

1050 Massachusetts Avenue

Cambridge, MA 02138

November 2013

The views expressed herein are those of the authors and do not necessarily reflect the views of the National Bureau of Economic Research.

NBER working papers are circulated for discussion and comment purposes. They have not been peerreviewed or been subject to the review by the NBER Board of Directors that accompanies official NBER publications.

(C) 2013 by Eric M. Leeper and Xuan Zhou. All rights reserved. Short sections of text, not to exceed two paragraphs, may be quoted without explicit permission provided that full credit, including $₫$ notice, is given to the source. 
Inflation's Role in Optimal Monetary-Fiscal Policy

Eric M. Leeper and Xuan Zhou

NBER Working Paper No. 19686

November 2013

JEL No. E31,E52,E62,E63

\begin{abstract}
$\underline{\text { ABSTRACT }}$
We study how the maturity structure of nominal government debt affects optimal monetary and fiscal policy decisions and equilibrium outcomes in the presence of distortionary taxes and sticky prices. Key findings are: (1) there is always a role for current and future inflation innovations to revalue government debt, reducing reliance on distorting taxes; (2) the role of inflation in optimal fiscal financing increases with the average maturity of government debt; (3) as average maturity rises, it is optimal to tradeoff inflation for output stabilization; (4) inflation is relatively more important as a fiscal shock absorber in high-debt than in low-debt economies; (5) in some calibrations that are relevant to U.S. data, welfare under the fully optimal monetary and fiscal policies can be made equivalent to the welfare under the conventional optimal monetary policy with passively adjusting lump-sum taxes by extending the average maturity of bond.
\end{abstract}

Eric M. Leeper

Department of Economics

304 Wylie Hall

Indiana University

Bloomington, IN 47405

and Monash University, Australia

and also NBER

eleeper@indiana.edu

Xuan Zhou

Department of Economics

105 Wylie Hall

Indiana University

Bloomington, IN 47405

xuanzhou@indiana.edu 


\title{
Inflation's Role in Optimal Monetary-Fiscal Policy*
}

\author{
Eric M. Leeper ${ }^{\dagger} \quad$ Xuan Zhou ${ }^{\ddagger}$
}

\section{INTRODUCTION}

Many countries have adopted monetary and fiscal policy arrangements that erect firm walls between the two policy authorities. There are good historical reasons for this separation: high- or hyperinflation episodes have sprung from governments pressuring central banks to finance spending by printing high-powered money. This policy separation is consistent with what Kirsanova et al. (2009) call the "current consensus assignment": task monetary policy with controlling demand and inflation and give fiscal policy the job of stabilizing debt.

Schmitt-Grohé and Uribe (2004) and Siu (2004) buttress the case for separating monetary and fiscal policies with the striking result that even a modicum of price stickiness implies an optimal policy mix of nearly constant inflation, while taxes adjust to fully finance government spending disturbances, just as in Barro (1979) and Aiyagari et al. (2002). Schmitt-Grohé and Uribe (2007) extend their findings to show that optimal "implementable" rules also entail the consensus assignment, an outcome later confirmed by Kirsanova and Wren-Lewis (2012), among others. The consensus assignment takes inflation financing off the table.

Economic theory does not generally support the complete separation of policy tasks. Phelps (1973) is the classic argument that in a second-best world, optimal policy calls for a positive inflation rate to balance distortions among various taxes against each other. In a stochastic world, the optimal inflation rate will vary over time. From this optimal public finance perspective, the complete separation of monetary and fiscal policies enshrined in the consensus is difficult to rationalize. Phelps's argument also finds voice in neoclassical models with flexible wages and prices, where Chari and Kehoe (1999) show that an optimal policy generates jumps in inflation that revalue nominal government debt without requiring changes in distorting tax rates, much as inflation behaves under the fiscal theory of the price level [Leeper (1991), Sims (1994), Woodford (1995)].

Phelps's policy prescription raises the practical question of whether the optimal inflation rate fluctuates enough to justify considering policy arrangements that do not separate

\footnotetext{
*November 24, 2013. We thank Jon Faust, Dale Henderson, Campbell Leith, Bruce Preston, Shu-Chun Susan Yang, Tack Yun and participants at seminars at the Korean Development Institute and the Federal Reserve Board for comments.

†Indiana University, Monash University and NBER; eleeper@indiana.edu.

${ }^{\ddagger}$ Indiana University; xuanzhou@indiana.edu.
} 
monetary and fiscal policy. After all, many economists believe that in advanced economies seigniorage is such a minor source of revenues that it can be ignored in policy design. ${ }^{1}$

Missing from the work that builds on Phelps's insights is the recognition that when the government issues long-term nominal debt, which most countries do in overwhelming proportions of total debt, surprise changes in current inflation and interest rates - even rather modest changes - can have substantial effects on the market value of debt, to become a sizeable source of fiscal financing. Hall and Sargent (2011) and Sims (2013) document that these surprise changes are not at all small potatoes: Hall and Sargent compute that about 16 percentage points of the 80 percentage point decline in the U.S. debt-GDP ratio from 1945 to 1974 is attributable to negative real returns due to realized inflation; Sims estimates the surprise capital gains and losses on federal debt to be the same order of magnitude as fluctuations in primary surpluses, about 6 percent of outstanding debt. Even when seigniorage revenues are small, surprise changes in current and future inflation may play a major role in fiscal financing. This paper abstracts from seigniorage to focus on revaluations of outstanding debt by surprise inflation and interest rates.

Sims $(2001,2013)$ questions whether the consensus assignment is robust when governments issue long-term nominal bonds. He lays out a theoretical argument for using nominal debt - and surprise revaluations of that debt - as a cushion against fiscal shocks to substitute for large movements in distorting taxes. Sims (2013) stops short of claiming that the weak responses of taxes to fiscal disturbances, which long debt permits, is optimal policy. This paper explores that claim.

The paper follows most closely the linear-quadratic approach that Benigno and Woodford (2004, 2007) developed. Deviations from optimality stem from the presence of distorting taxes, nominal price rigidities, and a distorted steady state. Policy chooses sequences of tax rates and short-term nominal interest rates to maximize a representative agent's utility subject to four constraints, given a government debt maturity structure: a consumption Euler equation, a Phillips curve, a government solvency condition, and a term structure relation. Government issues a portfolio of nominal bonds whose average maturity is indexed by a single parameter, as in Woodford (1998). Like Benigno and Woodford, we assume commitment and a timeless perspective.

A major focus of the paper is the role that the maturity structure of nominal government debt plays in the optimal policy mix. Most work in this literature, including that underlying the consensus assignment, imposes that the government issues only one-period bonds. Under this assignment, the maturity structure of government debt plays no obvious macro stabilization goal, at least in conventional policy models.

The paper offers a theoretical rationale for the empirical fact that governments revalue outstanding debt with surprise changes in inflation and interest rates. While this has been hinted at in previous work by Sims $(2001,2013)$, the present paper is the first to show that the revaluations are an essential component of optimal monetary and fiscal policies when government debt has average maturities in the ranges observed.

Maturity structure plays a subtle role in determining the impacts of monetary and fiscal

\footnotetext{
${ }^{1}$ King and Plosser (1985) observe that in the United States, seigniorage is about as important a source of revenues as excise taxes. King (1995) reports that over the 45 years between 1950 and 1994, seigniorage averaged 0.7 percent of GDP across the G-7 countries.
} 
policies. Two effects arise as the average maturity of debt extends. First, longer maturity can relieve some of the fiscal needs that arise from fluctuations in technology, wage markups, and government purchases. Second, longer maturity permits future monetary policy choices of short-term nominal interest rates to contribute to fiscal finance by changing bond prices and, therefore, the market value of debt. Taken together, as maturity extends, it becomes optimal to trade inflation stabilization off in favor of output stabilization and it is no longer optimalas it is under the consensus assignment - to fully stabilize inflation and allow output to bear the brunt of fiscal solvency needs.

We calibrate the model to quantify the fiscal financing effects for a country like the United States. With a post-war mean debt-GDP ratio of $46 \%$, it is optimal for a country like America to rely on surprise current and future inflation to finance about $7 \%$ of an innovation in fiscal needs when the average maturity is 5 years. High-debt countries, though, would optimally rely more heavily on inflation: about $11 \%$ with 5 -year average maturity. Reliance on surprise inflation and interest rates rises monotonically with average maturity.

Table 1 reports the average term to maturity of outstanding government debt in selected advanced economies in recent years. While there is variation across countries, with Korea at 16 quarters and the United Kingdom at 49 quarters, the median is about six years. We show below that the presence of even moderate average maturity government bonds can substantially alter the nature of optimal monetary and fiscal policies.

\begin{tabular}{ll} 
Country & Quarters \\
\hline \hline Canada & 26.1 \\
France & 25.6 \\
Germany & 24.0 \\
Italy & 24.3 \\
Japan & 22.1 \\
South Korea & 15.9 \\
United Kingdom & 49.3 \\
United States & 20.0 \\
\hline
\end{tabular}

Table 1: Average maturity of outstanding government debt, 1997-2010; Japan 1997-2009; South Korea 2001-2010. Source: OECD.

In the presence of distorting taxes, nominal rigidities, and long-term nominal government debt, policy faces a fundamental tradeoff between smoothing inflation and output - the two objectives in the representative agents' loss function - and ensuring government solvency. Government debt maturity affects how policy optimally makes this tradeoff. For both inflation and output, longer average maturity enhances smoothing. In terms of responding to fiscal needs, maturity affects inflation and output differently: longer maturity makes it optimal to allow inflation to react more strongly to shocks in fiscal needs, while the output gap responds less strongly.

In the extreme case of only one-period debt, which underlies the work behind the consensus assignment, optimal policy makes the price level a martingale-perfectly smoothes it - and forces the output gap to absorb disturbances. When nominal government bonds 
are perpetuities, optimal outcomes are starkly different: the output gap is a martingale and inflation adjusts permanently to exogenous shocks.

Key findings include: (1) there is always a role for current and future inflation innovations to revalue government debt, reducing reliance on distorting taxes; (2) the role of inflation in optimal fiscal financing increases with the average maturity of government debt; (3) as average maturity rises, it is optimal to tradeoff inflation for output stabilization; (4) inflation is relatively more important as a fiscal shock absorber in high-debt than in lowdebt economies; (5) in some calibrations that are relevant to U.S. data, welfare under the fully optimal monetary and fiscal policies can be made equivalent to the welfare under the conventional optimal monetary policy with passively adjusting lump-sum taxes by extending the average maturity of bond.

Contacts with Literature We integrate two strands of literature. First, following the neoclassical literature on optimal taxation, when the government has access only to distortionary taxes, variations in tax rates generate dead-weight losses [Barro (1979)]. Maximization of welfare calls for smoothing tax rates. If a disturbance to the government budget occurs, the real value of government debt should adjust with the shock. This is possible only when (i) the government can issue state-contingent bonds [Lucas and Stokey (1983), Chari et al. (1994)], or (ii) the government issues nominal bonds, but unexpected variations in inflation replicate state-contingent bonds [Bohn (1990) and Chari and Kehoe (1999)]. Neoclassical work abstracts from monetary considerations by assuming flexible prices.

Another strand, the new Keynesian literature on optimal monetary policy, emphasizes that when prices are sticky, variation in aggregate price levels creates price dispersion that is an important source of welfare loss. A benevolent government minimizes price volatility. This strand tends to abstract from fiscal considerations by assuming non-distorting sources of revenue that maintain government solvency [Clarida et al. (1999) and Woodford (2003)].

We also connect to studies that focus on long-term bonds. Angeletos (2002) and Buera and Nicolini (2004) examine the optimal maturity structure of public debt to find that statecontingent debt can be constructed by non-contingent debt with different maturities. They consider only the case where prices are perfectly flexible and the government issues only real debt. Woodford (1998), Cochrane (2001) and Sims (2001, 2013) study nominal government debt to argue that when outstanding government debt has long maturity, it can be optimal to finance higher government spending with a little bit of inflation spread over the maturity of the debt, effectively converting nominal debt into state-contingent real debt, as in Lucas and Stokey (1983). Both Cochrane and Sims employ ad hoc welfare functions to illustrate their points, so neither argues that revaluation of debt through inflation is a feature of a fully optimal policy. More importantly, they both consider a constant or exogenous real interest rate, downplaying intertemporal effects of monetary and fiscal policies.

\section{MODEL}

We employ a standard new Keynesian economy that consists of a representative household with an infinite planning horizon, a collection of monopolistically competitive firms that produce differentiated goods, and a government. A fiscal authority finances exogenous expenditures with distorting taxes and debt and a monetary authority sets the short-term 
nominal interest rate.

2.1 Households The economy is populated by a continuum of identical households. Each household has preferences defined over consumption, $C_{t}$, and hours worked, $N_{j t}$. Preferences are

$$
E_{0} \sum_{t=0}^{\infty} \beta^{t} U\left(C_{t}, N_{j t}\right)=E_{0} \sum_{t=0}^{\infty} \beta^{t}\left[\frac{C_{t}^{1-\sigma}}{1-\sigma}-\int_{0}^{1} \frac{N_{j t}^{1+\varphi}}{1+\varphi} d j\right]
$$

where $\sigma^{-1}$ parameterizes the intertemporal elasticity of substitution, and $\varphi^{-1}$ parametrizes the Frisch elasticity of labor supply.

Consumption is a CES aggregator defined over a basket of goods of measure one and indexed by $j$

$$
C_{t}=\left[\int_{0}^{1} C_{j t}^{\frac{\epsilon-1}{\epsilon}} d j\right]^{\frac{\epsilon}{\epsilon-1}}
$$

where $C_{j t}$ represents the quantity of good $j$ consumed by the household in period $t$. The parameter $\epsilon>1$ denotes the intratemporal elasticity of substitution across different varieties of consumption goods. ${ }^{2}$ Each good $j$ is produced using a type of labor that is specific to that industry, and $N_{j t}$ denotes the quantity of labor supply of type $j$ in period $t$. The representative household supplies all types of labor.

The aggregate price index $P_{t}$ is

$$
P_{t}=\left[\int_{0}^{1} P_{j t}^{1-\epsilon} d j\right]^{\frac{1}{1-\epsilon}}
$$

where $P_{j t}$ is the nominal price of the final goods produced in industry $j$.

Households maximize expected utility subject to the budget constraint

$$
C_{t}+Q_{t}^{S} \frac{B_{t}^{S}}{P_{t}}+Q_{t}^{M} \frac{B_{t}^{M}}{P_{t}}=\frac{B_{t-1}^{S}}{P_{t}}+\left(1+\rho Q_{t}^{M}\right) \frac{B_{t-1}^{M}}{P_{t}}+\int_{0}^{1}\left(\frac{W_{j t}}{P_{t}} N_{j t}+\Pi_{j t}\right) d j+Z_{t}
$$

where $W_{j t}$ is the nominal wage rate in industry $j, \Pi_{j t}$ is the share of profits paid by the $j$ th industry to the households, and $Z_{t}$ is lump-sum government transfer payments. $B_{t}^{S}$ is a one-period government bond with nominal price $Q_{t}^{S} ; B_{t}^{M}$ is a long-term government bond portfolio with price $Q_{t}^{M}$. The long-term bond portfolio is defined as perpetuities with coupons that decay exponentially, as in Woodford (2001). A bond issued at date $t$ pays $\rho^{k-1}$ dollars at date $t+k$, for $k \geq 1$ and $\rho \in[0,1]$ is the coupon decay factor that parameterizes the average maturity of the bond portfolio. A consol is the special case when $\rho=1$ and one-period bonds arise when $\rho=0$. The duration of the long-term bond portfolio $B_{t}^{M}$ is $(1-\beta \rho)^{-1}$.

\footnotetext{
${ }^{2}$ When $\epsilon \rightarrow \infty$, goods become perfect substitutes; when $\epsilon \rightarrow 1$, goods are neither substitutes nor complements: an increase in the price of one good has no effect on demand for other goods.
} 
Household optimization yields the first-order conditions

$$
\begin{aligned}
\frac{W_{j t}}{P_{t}} & =-\mu_{t}^{W} \frac{U_{n_{j}, t}}{U_{c, t}} \\
Q_{t}^{S} & =\beta E_{t} \frac{U_{c, t+1}}{U_{c, t}} \frac{P_{t}}{P_{t+1}} \\
Q_{t}^{M} & =\beta E_{t} \frac{U_{c, t+1}}{U_{c, t}} \frac{P_{t}}{P_{t+1}}\left(1+\rho Q_{t+1}^{M}\right)
\end{aligned}
$$

where $\mu_{t}^{W}$ is an exogenous wage markup factor. ${ }^{3}$ Combining (2) and (3) yields the noarbitrage condition between one-period and long-term bonds

$$
Q_{t}^{M}=E_{t} Q_{t}^{S}\left(1+\rho Q_{t+1}^{M}\right)
$$

2.2 Firms A continuum of monopolistically competitive firms produce differentiated goods. Production of good $j$ is given by

$$
Y_{j t}=A_{t} N_{j t}
$$

where $A_{t}$ is an exogenous aggregate technology shock, common across firms. Firm $j$ faces the demand schedule

$$
Y_{j t}=\left(\frac{P_{j t}}{P_{t}}\right)^{-\epsilon} Y_{t}
$$

With demand imperfectly price-elastic, each firm has some market power, leading to the monopolistic competition distortion in the economy.

Another distortion stems from nominal rigidities. Prices are staggered, as in Calvo (1983), with a fraction $1-\theta$ of firms permitted to choose a new price, $P_{t}^{*}$, each period, while the remaining firms cannot adjust their prices. This pricing behavior implies the aggregate price index

$$
P_{t}=\left[(1-\theta)\left(P_{t}^{*}\right)^{1-\epsilon}+\theta\left(P_{t-1}\right)^{1-\epsilon}\right]^{\frac{1}{1-\epsilon}}
$$

Firms that can reset their price choose $P_{t}^{*}$ to maximize the expected sum of discounted future profits by solving

$$
\max E_{t} \sum_{k=0}^{\infty} \theta^{k} Q_{t, t+k}\left[\left(1-\tau_{t+k}\right) P_{t}^{*} Y_{t+k \mid t}-\Psi_{t+k}\left(Y_{t+k \mid t}\right)\right]
$$

subject to the demand schedule

$$
Y_{t+k \mid t}=\left(\frac{P_{t}^{*}}{P_{t+k}}\right)^{-\epsilon} Y_{t+k}
$$

\footnotetext{
${ }^{3}$ We follow Benigno and Woodford (2007) to include the time-varying exogenous wage markup in order to include a "pure" cost-push effect.
} 
where $Q_{t, t+k}$ is the stochastic discount factor for the price at $t$ of one unit of composite consumption goods at $t+k$, defined by $Q_{t, t+k}=\beta^{k} \frac{U_{c, t+k}}{U_{c, t}} \frac{P_{t}}{P_{t+k}}$. Sales revenues are taxed at rate $\tau_{t}, \Psi_{t}$ is cost function, and $Y_{t+k \mid t}$ is output in period $t+k$ for a firm that last reset its price in period $t$.

The first-order condition for this maximization problem implies that the newly chosen price in period $t, P_{t}^{*}$, satisfies

$$
\begin{aligned}
\left(\frac{P_{t}^{*}}{P_{t}}\right)^{1+\epsilon \varphi} & =\frac{\epsilon}{\epsilon-1} \frac{E_{t} \sum_{k=0}^{\infty}(\beta \theta)^{k} \mu_{t+k}^{W}\left(\frac{Y_{t+k}}{A_{t+k}}\right)^{\varphi+1}\left(\frac{P_{t+k}}{P_{t}}\right)^{\epsilon(1+\varphi)}}{\sum_{i=0}^{\infty}(\beta \theta)^{k}\left(1-\tau_{t+k}\right) U_{c, t+k} Y_{t+k}\left(\frac{P_{t+k}}{P_{t}}\right)^{\epsilon-1}} \\
& =\frac{\epsilon}{\epsilon-1} \frac{K_{t}}{J_{t}}
\end{aligned}
$$

where $K_{t}$ and $J_{t}$ are aggregate variables that satisfy the recursive relations

$$
\begin{aligned}
& K_{t}=\mu_{t}^{W}\left(\frac{Y_{t}}{A_{t}}\right)^{\varphi+1}+\beta \theta E_{t} K_{t+1} \pi_{t+1}^{\epsilon(1+\varphi)} \\
& J_{t}=\left(1-\tau_{t}\right) U_{c, t} Y_{t}+\beta \theta E_{t} J_{t+1} \pi_{t+1}^{\epsilon-1}
\end{aligned}
$$

2.3 Government The government consists of a monetary and a fiscal authority who face the consolidated budget constraint, expressed in real terms

$$
\frac{\left(1+\rho Q_{t}^{M}\right) B_{t-1}^{M}}{P_{t}}=\frac{Q_{t}^{M} B_{t}^{M}}{P_{t}}+S_{t}
$$

where $S_{t}$ is the real primary budget surplus defined as

$$
S_{t}=\tau_{t} Y_{t}-Z_{t}-G_{t}
$$

$G_{t}$ is government demand for the composite goods and $Z_{t}$ is government transfer payments. We consider a fiscal regime in which both $G_{t}$ and $Z_{t}$ are exogenous processes and only $\tau_{t}$ adjusts endogenously to ensure government solvency. This assumption breaks Ricardian equivalence, so the government's budget and the dynamics of public debt matter for welfare and monetary policy can have important fiscal consequences.

An intertemporal equilibrium - or solvency - condition links the real market value of outstanding government bonds to the expected present value of primary surpluses ${ }^{4}$

$$
\left(1+\rho Q_{t}^{M}\right) \frac{B_{t-1}^{M}}{P_{t}}=E_{t} \sum_{k=0}^{\infty} R_{t, t+k} S_{t+k}
$$

where $R_{t, t+k}=\beta^{k} \frac{U_{c, t+k}}{U_{c, t}}$ is the $k$-period real discount factor.

The left-hand side of (11) highlights a key role of long-term bonds. With only one-period bonds, $\rho=0$, the nominal value of outstanding government bonds, $B_{t-1}^{M}$, is predetermined, so an unexpected change to the present value of primary surpluses must be absorbed entirely

\footnotetext{
${ }^{4}$ See Appendix A for the derivation of this condition.
} 
by surprise inflation or deflation at time $t$. Long-term bonds, $\rho>0$, imply that the nominal value of government bond, $\left(1+\rho Q_{t}^{M}\right) B_{t-1}^{M}$, is no longer predetermined. Because the nominal bond price $Q_{t}^{M}$, depends on expected future riskless short-term nominal interest rates ${ }^{5}$

$$
Q_{t}^{M}=E_{t} \sum_{k=0}^{\infty} \frac{\rho^{k}}{i_{t} i_{t+1} \ldots i_{t+k}}
$$

solvency condition (11) may be written as

$$
\underbrace{\left[1+E_{t} \sum_{k=0}^{\infty} \frac{\rho^{k}}{i_{t} i_{t+1} \ldots i_{t+k}}\right]}_{\text {current and future monetary policy }} \frac{B_{t-1}^{M}}{P_{t}}=\underbrace{E_{t} \sum_{k=0}^{\infty} R_{t, t+k} S_{t+k}}_{\text {current and future fiscal policy }}
$$

Now an unexpected change to the present value of primary surpluses could be absorbed by adjustments in current and future nominal interest rates, reducing the reliance on current inflation.

Equilibrium condition (13) reflects a fundamental symmetry between monetary and fiscal policies. The price level today must be consistent with expected future monetary and fiscal policies, whether those policies are set optimally or not. Bond maturity matters: so long as the average maturity exceeds one period, $\rho>0$, expected future monetary policy in the form of choices of the short-term nominal interest rate, $i_{t+k}$, plays a role in determining the current price level.

\subsection{EquilibRium Market clearing in the goods market requires}

$$
Y_{t}=C_{t}+G_{t}
$$

and market clearing in labor market requires

$$
\Delta_{t}^{\frac{1}{1+\varphi}} Y_{t}=A_{t} N_{t}
$$

where $\Delta_{t}=\int_{0}^{1}\left(\frac{P_{j t}}{P_{t}}\right)^{-\epsilon(1+\varphi)} d j$ denotes the the measure of price dispersion across firms and satisfies the recursive relation

$$
\Delta_{t}=(1-\theta)\left[\frac{1-\theta \pi_{t}^{\epsilon-1}}{1-\theta}\right]^{\frac{\epsilon(1+\varphi)}{\epsilon-1}}+\theta \pi_{t}^{\epsilon(1+\varphi)} \Delta_{t-1}
$$

Price dispersion is the source of welfare losses from inflation variability.

\section{Fully Optimal Policy}

In the fully optimal policy problem, government chooses functions for the tax rate, $\tau_{t}$, and the short-term nominal interest rate, $i_{t}$, taking exogenous processes for technology, $A_{t}$, the wage markup, $\mu_{t}^{W}$, government purchases, $G_{t}$, and transfers, $Z_{t}$, as given. We derive how the optimal policy and welfare vary with the average maturity of government debt, as indexed by $\rho$. We consider the case of a steady state distorted by distortionary tax and monopolistic competition and focus on optimal policy commitment, adopting Woodford's (2003) "timeless perspective."

\footnotetext{
${ }^{5}$ The riskless short-term nominal gross interest rate is defined by $i_{t}=\left[Q_{t}^{S}\right]^{-1}$. See Appendix $\mathrm{A}$ for the derivation of condition (12).
} 
3.1 Linear-Quadratic Approximation We compute a linear-quadratic approximation to the nonlinear optimal solutions, using the methods that Benigno and Woodford (2004) develop. This allows us to characterize the optimal policy responses to fluctuations in the exogenous disturbance processes within a neighborhood of the steady state.

In this model, distorting taxes and monopolistic competition conspire to make the deterministic steady state inefficient, so an ad hoc linear-quadratic representation of the problem does not yield an accurate approximation of the optimal policy. ${ }^{6}$ Benigno and Woodford (2004) show that a correct linear-quadratic approximation is still possible by properly utilizing information from micro-foundations. Their approach computes a second-order approximation to the model's structural equations and uses an appropriate linear combination of those equations to eliminate the linear terms in the second-order approximation to the welfare measure to obtain a purely quadratic expression.

We follow Benigno and Woodford's micro-founded linear-quadratic approach for three reasons. First, it allows us to obtain neat analytical solutions that help us to characterize the properties of optimal policies and separate out the channels through which long-term bonds affect optimal allocation. Second, the framework nests conventional analyses of both optimal inflation-smoothing and optimal tax-smoothing, providing an integrated approach to the two literatures. Third, the quadratic welfare criterion is independent of policy, which permits us to compare our results to alternative sub-optimal policies.

Welfare losses experienced by the representative household are, up to a second-order approximation, proportional to ${ }^{7}$

$$
\frac{1}{2} E_{0} \sum_{t=0}^{\infty} \beta^{t}\left(q_{\pi} \hat{\pi}_{t}^{2}+q_{x} \hat{x}_{t}^{2}\right)
$$

where the relative weight on output stabilization depends on model parameters

$$
\frac{q_{x}}{q_{\pi}} \equiv \frac{\kappa}{\epsilon}\left[1+\frac{s_{c}^{-1} \sigma}{\varphi+s_{c}^{-1} \sigma} \frac{\left(1+w_{g}\right)\left(1+w_{\tau}\right)-s_{c}^{-1}\left(1+w_{g}+w_{\tau}\right)}{\left(\Phi^{-1}-1\right) \Gamma+\left(1+w_{g}\right)(1+\varphi)}\right]
$$

$\hat{x}_{t}$ denotes the welfare-relevant output gap, defined as the deviation between $\hat{Y}_{t}$ and its efficient level $\hat{Y}_{t}^{e}, \hat{x}_{t} \equiv \hat{Y}_{t}-\hat{Y}_{t}^{e}$. Efficient output, $\hat{Y}_{t}^{e}$, depends on the four fundamental shocks and is given by $\hat{Y}_{t}^{e}=q_{A} \hat{A}_{t}+q_{G} \hat{G}_{t}+q_{Z} \hat{Z}_{t}+q_{W} \mu_{t}^{W}{ }^{8} w_{g}=(\bar{Z}+\bar{G}) / \bar{S}$ is the steadystate government outlays to surplus ratio, $w_{\tau}=\bar{\tau} / 1-\bar{\tau}, s_{c}=\bar{C} / \bar{Y}$ is the steady-state consumption to GDP ratio, and

$$
\begin{aligned}
\kappa & =\frac{(1-\theta)(1-\beta \theta)}{\theta} \frac{s_{c}^{-1} \sigma+\varphi}{1+\epsilon \varphi} \\
\Gamma & =\left(s_{c}^{-1} \sigma+\varphi\right)\left(1+w_{g}\right)+s_{c}^{-1} \sigma w_{\tau}-w_{\tau}\left(1+w_{g}\right) \\
\Phi & =1-(1-\bar{\tau}) \frac{\epsilon-1}{\epsilon}
\end{aligned}
$$

\footnotetext{
${ }^{6}$ One convenient way to eliminate the inefficiency of the steady state is to assume an employment subsidy that offsets the distortion due to the market power of monopolistically-competitive price-setters or distorting tax, so that the steady state with zero inflation involves an efficient level of output. We instead consider a more realistic case, where an employment subsidy is not available. See Kim and Kim (2003) and Woodford (2011) for more discussions.

${ }^{7}$ See Appendices $\mathrm{C}-\mathrm{F}$ for detailed derivations.

${ }^{8}$ Parameters $q_{A}, q_{G}, q_{Z}$ and $q_{W}$ are defined in appendix $\mathrm{F}$.
} 
Note that $-\frac{U_{n}}{U_{c}}=(1-\Phi) M P N$, so $\Phi$, which measures the inefficiency of the steady state, depends on the steady state tax rate, $\bar{\tau}$, and the elasticity of substitution between differentiated goods, $\epsilon$.

3.2 Linear Constraints Constraints on the optimization problem come from log-linear approximations to the model equations. The first constraint comes from the aggregate supply relation between current inflation and the output gap

$$
\hat{\pi}_{t}=\beta E_{t}\left[\hat{\pi}_{t+1}\right]+\kappa\left(\hat{x}_{t}+\psi \hat{\tau}_{t}\right)+u_{t}
$$

where $u_{t}$ is a composite cost-push shock that depends on the four exogenous disturbances

$$
u_{t} \equiv \underbrace{\kappa\left[q_{A}-\frac{1+\varphi}{\varphi+\sigma s_{c}^{-1}}\right]}_{u_{A}} \hat{A}_{t}+\underbrace{\kappa\left[q_{G}-\frac{\sigma}{\varphi+\sigma s_{c}^{-1}} \frac{s_{g}}{s_{c}}\right]}_{u_{G}} \hat{G}_{t}+\underbrace{\kappa q_{Z}}_{u_{Z}} \hat{Z}_{t}+\underbrace{\kappa\left[q_{W}+\frac{1}{\varphi+\sigma s_{c}^{-1}}\right]}_{u_{W}} \hat{\mu}_{t}^{W}
$$

The exogenous disturbances generate cost-push effects through (19) because with a distorted steady state, they generate a time-varying gap between the flexible-price equilibrium level of output and the efficient level of output. If the steady state were not distorted, only variations in wage markups would have cost-push effects. This is why wage markups are regarded as "pure" cost-push disturbances. ${ }^{9}$

When $\hat{\tau}_{t}$ is exogenous, $\kappa \psi \hat{\tau}_{t}+u_{t}$ prevents complete stabilization of inflation and the welfare-relevant output gap. Iterating forward on (18) yields

$$
\hat{\pi}_{t}=E_{t} \sum_{k=0}^{\infty} \beta^{k} \kappa \hat{x}_{t+k}+U_{t}
$$

where $U_{t} \equiv E_{t} \sum_{k=0}^{\infty} \beta^{k}\left(\kappa \psi \hat{\tau}_{t+k}+u_{t+k}\right)$ determines the degree to which stabilization of inflation and output gap is not possible. This is the only source of tradeoff between stabilization of inflation and output gap in conventional new Keynesian optimal monetary policy analyses [for example, Galí (1991)].

When $\hat{\tau}_{t}$ is chosen optimally along with monetary policy, then $\hat{\tau}_{t}$ can be set to fully absorb cost-push shocks, making simultaneous stabilization of inflation and the output gap possible. Benigno and Woodford (2004) rewrite (18) as

$$
\hat{\pi}_{t}=\beta E_{t}\left[\hat{\pi}_{t+1}\right]+\kappa \hat{x}_{t}+\kappa \psi\left(\hat{\tau}_{t}-\hat{\tau}_{t}^{*}\right)
$$

where $\hat{\tau}_{t}^{*} \equiv-\frac{1}{\kappa \psi} u_{t}$ is the tax rate that offsets the cost-push shock. Expression (20) describes the tradeoff between inflation and output that fiscal policy faces because tax rates can help stabilize output and inflation by offsetting variations in cost-push distortions.

A second constraint arises from the household's Euler equation. After imposing market clearing it may be written as

$$
\hat{x}_{t}=E_{t}\left[\hat{x}_{t+1}\right]-\frac{s_{c}}{\sigma}\left(\hat{i}_{t}-E_{t}\left[\hat{\pi}_{t+1}\right]\right)+v_{t}
$$

\footnotetext{
${ }^{9}$ See Benigno and Woodford (2004) for detailed discussions.
} 
where the composite aggregate demand shock, $v_{t}$, is

$$
v_{t} \equiv \underbrace{q_{A}\left(\rho_{A}-1\right)}_{v_{A}} \hat{A}_{t}+\underbrace{\left(q_{G}-s_{g}\right)\left(\rho_{G}-1\right)}_{v_{G}} \hat{G}_{t}+\underbrace{q_{Z}\left(\rho_{Z}-1\right)}_{v_{Z}} \hat{Z}_{t}+\underbrace{q_{W}\left(\rho_{W}-1\right)}_{v_{W}} \hat{\mu}_{t}^{W}
$$

Alternatively, (21) can be written as

$$
\hat{x}_{t}=E_{t}\left[\hat{x}_{t+1}\right]+\frac{s_{c}}{\sigma} E_{t}\left[\hat{\pi}_{t+1}\right]-\frac{s_{c}}{\sigma}\left(\hat{i}_{t}-\hat{i}_{t}^{*}\right)
$$

where $\hat{i}_{t}^{*} \equiv \frac{\sigma}{s_{c}} v_{t}$ is the setting of the short-term nominal interest rate that exactly offsets the composite demand-side shock. ${ }^{10}$ Expression (23) makes clear how monetary policy can offset variations in demand-side distortions.

If (20) and (23) were the only constraints facing policy makers, it would be possible to choose monetary and tax policies to completely stabilize inflation and output. Policy could achieve the first-best outcome, $\hat{\pi}_{t}=\hat{x}_{t}=0$, by setting

$$
\hat{\tau}_{t}=\hat{\tau}_{t}^{*} \quad \hat{i}_{t}=\hat{i}_{t}^{*}
$$

In the absence of any additional constraints on the policy problem, policy authorities who are free to choose paths for the short-term nominal interest rate and tax rate can achieve the unconstrained maximum of welfare. To achieve this first-best outcome, policy must have access to a non-distorting source of revenues or state-contingent debt that can adjust to ensure that the government's solvency requirements do not impose additional restrictions on achievable outcomes.

When non-distorting revenues are not available, the government can convert nominal bonds into state-dependent real bonds. If the government issues nominal bonds with average maturity indexed by $\rho$, fiscal solvency implies the additional constraint

$$
\hat{b}_{t-1}^{M}+f_{t}=\beta \hat{b}_{t}^{M}+(1-\beta) \frac{\bar{\tau}}{s_{d}}\left(\hat{\tau}_{t}+\hat{x}_{t}\right)+\hat{\pi}_{t}+\beta(1-\rho) \hat{Q}_{t}^{M}
$$

where $s_{d} \equiv \bar{S} / \bar{Y}$ is the steady-state surplus to output ratio and $f_{t}$ is a composite fiscal shock that reflects all four exogenous disturbances to the government's flow constraint

$$
f_{t} \equiv \underbrace{-(1-\beta) \frac{\bar{\tau}}{s_{d}} q_{A}}_{f_{A}} \hat{A}_{t}+\underbrace{(1-\beta)\left(\frac{s_{g}}{s_{d}}-\frac{\bar{\tau}}{s_{d}} q_{G}\right)}_{f_{G}} \hat{G}_{t}+\underbrace{(1-\beta)\left(\frac{s_{z}}{s_{d}}-\frac{\bar{\tau}}{s_{d}} q_{Z}\right)}_{f_{Z}} \hat{Z}_{t} \underbrace{-(1-\beta) \frac{\bar{\tau}}{s_{d}} q_{W}}_{f_{W}} \hat{\mu}_{t}^{W}
$$

In general, all disturbances have fiscal consequences through (25) and (26), because nondistorting taxes are not available to offset their impacts on the government's budget.

Absence of arbitrage between short-term and long-term bonds delivers the fourth constraint on the optimal policy program

$$
\beta \rho E_{t} \hat{Q}_{t+1}^{M}=\hat{Q}_{t}^{M}+\hat{i}_{t}
$$

\footnotetext{
${ }^{10}$ Note that $\hat{i}_{t}^{*}=\frac{\sigma}{s_{c}} E_{t}\left[\left(\hat{y}_{t+1}^{e}-\hat{y}_{t}^{e}\right)-s_{g}\left(\hat{G}_{t+1}-\hat{G}_{t}\right)\right]$, giving it an interpretation as the efficient level of the real interest rate.
} 
Iterating on (27) and applying a terminal condition yields

$$
\hat{Q}_{t}^{M}=-E_{t} \sum_{k=0}^{\infty}(\beta \rho)^{k} \hat{i}_{t+k}
$$

Defining the long-term interest rate $i_{t}^{M}$ as the yield to maturity, $i_{t}^{M} \equiv \frac{1}{Q_{t}^{M}}-(1-\rho)$, we obtain the term structure of interest rates

$$
\hat{i}_{t}^{M}=\frac{1-\beta \rho}{1-\beta} E_{t} \sum_{k=0}^{\infty}(\beta \rho)^{k} \hat{i}_{t+k}
$$

When $\rho=0$, all bonds are one period, $\hat{i}_{t}^{M}=\frac{1}{1-\beta} \hat{i}_{t}$, the long-term interest rate at time $t$ is proportional to the current short-term interest rate, so any disturbance to the long rate will also affect the current short rate. When $\rho>0$, the long-term interest rate at time $t$ is determined by the whole path of future short-term interest rates, making intertemporal smoothing possible. A disturbance to the long-term interest rate can be absorbed by adjusting future short-term interest rates, with no change in the current short rate. By separating current and future monetary policies, long bonds provide policy additional leverage.

Iterating forward on the government's budget constraint (25) and imposing transversality and the no-arbitrage condition (28), we obtain the intertemporal equilibrium condition

$$
\begin{aligned}
\underbrace{\hat{b}_{t-1}^{M}+F_{t}}_{\text {fiscal stress }}= & \hat{\pi}_{t}+\frac{\sigma}{s_{c}} \hat{x}_{t}+(1-\beta) E_{t} \sum_{k=0}^{\infty} \beta^{k}\left[b_{\tau}\left(\hat{\tau}_{t+k}-\hat{\tau}_{t+k}^{*}\right)+b_{x} \hat{x}_{t+k}\right] \\
& +\underbrace{E_{t} \sum_{k=0}^{\infty}(\beta \rho)^{k+1}\left(\hat{i}_{t+k}-\hat{i}_{t+k}^{*}\right)}_{\text {due to long-term bonds }}
\end{aligned}
$$

where $b_{\tau}=\frac{\bar{\tau}}{s_{d}}, b_{x}=\frac{\bar{\tau}}{s_{d}}-\frac{\sigma}{s_{c}}$ and

$$
F_{t}=E_{t} \sum_{k=0}^{\infty} \beta^{k} f_{t+k}-(1-\beta) \frac{\bar{\tau}}{s_{d}} E_{t} \sum_{k=0}^{\infty} \beta^{k} \hat{\tau}_{t+k}^{*}+E_{t} \sum_{k=0}^{\infty}\left[\beta^{k+1}-(\beta \rho)^{k+1}\right] \hat{i}_{t+k}^{*}
$$

The sum $\hat{b}_{t-1}^{M}+F_{t}$ summarizes the fiscal stress that prevents complete stabilization of inflation and the welfare-relevant output gap. Given the definitions of $\tau^{*}$ and $i^{*}, F_{t}$ reflects fiscal stress stemming from three conceptually distinct but related sources: the composite fiscal shock, $f_{t}$, the composite cost-push shock, $u_{t}$ (through $\tau_{t}^{*}$ ), and the composite aggregate demand shock, $v_{t}$ (through $\left.i_{t}^{*}\right){ }^{11}$

Contrasting (30) to the one-period bond case in Benigno and Woodford (2004), the presence of long-term bonds gives a role to expectations of future monetary policies. Monetary and fiscal policy can be coordinated so that households' expectations about future policies affect long-term interest rates to offset part of the overall fiscal stress in the economy.

\footnotetext{
${ }^{11} F_{t}$ corresponds to the fiscal stress that Benigno and Woodford (2004) define, but here it is extended to the case of long-term bonds.
} 
With $F_{t}$ fluctuating exogenously, complete stabilization of inflation and output, $\hat{\pi}_{t}=\hat{x}_{t}=$ 0 , which implies $\hat{\tau}_{t}=\hat{\tau}_{t}^{*}, \hat{i}_{t}=\hat{i}_{t}^{*}$, will not generally satisfy (30) and the government would be insolvent. The additional fiscal solvency constraint prevents the first-best allocation from being achievable. Any feasible allocation involves a tension between stabilization of inflation and output gap, so the optimal policy must balance this tension.

\section{Optimal Policy Analytics: Flexible Prices}

In this section we characterize optimal equilibrium and policy assignment for the special case of completely flexible prices. This case serves as a baseline, since with flexible prices the tradeoff between inflation and output gap disappears. It also connects to earlier work by Chari et al. (1996) and Chari and Kehoe (1999), except that they considered only real government bonds, while we consider nominal bonds. Flexible prices emerge when $\theta=0$, which implies $\kappa=\infty$ and $q_{\pi}=0$. Costless inflation converts the loss function from (17) to

$$
\frac{1}{2} E_{0} \sum_{t=0}^{\infty} \beta^{t} q_{x} \hat{x}_{t}^{2}
$$

and the optimal policy problem minimizes (32) subject to the sequence of constraints

$$
\begin{aligned}
& \hat{x}_{t}+\psi\left(\hat{\tau}_{t}-\hat{\tau}_{t}^{*}\right)=0 \\
& \hat{x}_{t}+\frac{s_{c}}{\sigma}\left(\hat{i}_{t}-\hat{i}_{t}^{*}\right)-E_{t}\left[\hat{x}_{t+1}\right]-\frac{s_{c}}{\sigma} E_{t}\left[\hat{\pi}_{t+1}\right]=0 \\
& \hat{b}_{t-1}^{M}+F_{t}=\hat{\pi}_{t}+\frac{\sigma}{s_{c}} \hat{x}_{t}+(1-\beta) E_{t} \sum_{k=0}^{\infty} \beta^{k}\left[b_{\tau}\left(\hat{\tau}_{t+k}-\hat{\tau}_{t+k}^{*}\right)+b_{x} \hat{x}_{t+k}\right] \\
&+E_{t} \sum_{k=0}^{\infty}(\beta \rho)^{k+1}\left(\hat{i}_{t+k}-\hat{i}_{t+k}^{*}\right)
\end{aligned}
$$

The optimal solution entails $\hat{x}_{t}=0$ at all times, which can be achieved if fiscal policy follows $\hat{\tau}_{t}=\hat{\tau}_{t}^{*}$ and monetary policy sets the short-term real interest rate as $\hat{i}_{t}-E_{t} \hat{\pi}_{t+1}=\hat{i}_{t}^{*}$. In this optimal policy assignment, fiscal policy stabilizes the output gap, monetary policy stabilizes expected inflation and the maturity structure of debt determines the timing of inflation. Equilibrium inflation satisfies

$$
\hat{b}_{t-1}^{M}+F_{t}=\hat{\pi}_{t}+E_{t} \sum_{k=1}^{\infty}(\beta \rho)^{k} \hat{\pi}_{t+k}
$$

so increases in factors that prevent complete stabilization of the objectives $\hat{b}_{t-1}^{M}+F_{t}$, raise the expected present value of inflation. When $\rho>0$, (36) implies that long-term bonds allow the government to trade off inflation today for inflation in the future. The longer the average maturity, the farther into the future inflation can be postponed. This conclusion is reminiscent of Cochrane's (2001) optimal inflation-smoothing result.

When $\rho=0$ and all bonds are one-period, (36) collapses to

$$
\hat{b}_{t-1}^{M}+F_{t}=\hat{\pi}_{t}
$$


and, as Benigno and Woodford (2007) emphasize, "optimal policy will involve highly volatile inflation and extreme sensitivity of inflation to fiscal shocks."

Flexible prices neglect the welfare costs of inflation. When prices are sticky and inflation volatility is costly, the optimal allocation should balance variations in inflation against variations in the output gap.

\section{Optimal Policy Analytics: Sticky Prices}

In the case where prices are sticky, the optimization problem finds paths for $\left\{\hat{\pi}_{t}, \hat{x}_{t}, \hat{\tau}_{t}, \hat{i}_{t}, \hat{b}_{t}^{M}, \hat{Q}_{t}^{M}\right\}$ that minimize

$$
\frac{1}{2} E_{0} \sum_{t=0}^{\infty} \beta^{t}\left[\hat{\pi}_{t}^{2}+\lambda \hat{x}_{t}^{2}\right], \quad \lambda \equiv \frac{q_{x}}{q_{\pi}}
$$

subject to the sequence of constraints

$$
\begin{aligned}
& \hat{\pi}_{t}=\beta E_{t}\left[\hat{\pi}_{t+1}\right]+\kappa \hat{x}_{t}+\kappa \psi\left(\hat{\tau}_{t}-\hat{\tau}_{t}^{*}\right) \\
& \hat{x}_{t}=E_{t}\left[\hat{x}_{t+1}\right]+\frac{s_{c}}{\sigma} E_{t}\left[\hat{\pi}_{t+1}\right]-\frac{s_{c}}{\sigma}\left(\hat{i}_{t}-\hat{i}_{t}^{*}\right) \\
& \hat{b}_{t-1}^{M}=\beta \hat{b}_{t}^{M}+(1-\beta) \frac{\bar{\tau}}{s_{d}}\left(\hat{\tau}_{t}+\hat{x}_{t}\right)+\hat{\pi}_{t}+\beta(1-\rho) \hat{Q}_{t}^{M}-f_{t} \\
& \hat{Q}_{t}^{M}=\beta \rho E_{t} \hat{Q}_{t+1}^{M}-\hat{i}_{t}
\end{aligned}
$$

Taking first-order conditions with respect to $\hat{\pi}_{t}, \hat{x}_{t}, \hat{i}_{t}, \hat{\tau}_{t}, \hat{b}_{t}^{M}$ and $\hat{Q}_{t}^{M}$, we obtain the following optimality conditions:

$$
\begin{array}{r}
\hat{\pi}_{t}=-\frac{1-\beta}{\kappa \psi} \frac{\bar{\tau}}{s_{d}}\left(L_{t}^{b}-L_{t-1}^{b}\right)-L_{t}^{b}+\frac{1}{\beta} L_{t-1}^{q} \\
\lambda \hat{x}_{t}=\left(\psi^{-1}-1\right)(1-\beta) \frac{\bar{\tau}}{s_{d}} L_{t}^{b}-\frac{\sigma}{s_{c}} L_{t}^{q}+\frac{\sigma}{s_{c}} \frac{1}{\beta} L_{t-1}^{q} \\
\beta(1-\rho) L_{t}^{b}-L_{t}^{q}+\rho L_{t-1}^{q}=0 \\
E_{t} L_{t+1}^{b}-L_{t}^{b}=0
\end{array}
$$

where $L_{t}^{b}$ and $L_{t}^{q}$ are Lagrange multipliers corresponding to (41) and (42). We solve (39)-(46) for state-contingent paths of $\left\{\hat{\pi}_{t}, \hat{x}_{t}, \hat{i}_{t}, \hat{\tau}_{t}, \hat{b}_{t}^{M}, \hat{Q}_{t}^{M}, L_{t}^{q}, L_{t}^{b}\right\}$.

With inflation and the output gap expressed as functions of only $L_{t}^{b}$ and $L_{t}^{q}$, it is clear that disturbances to the government budget or to debt maturity affect inflation and output. The shadow price of the government budget constraint, $L_{t}^{b}$, follows a martingale, according to (46), a property that reflects intertemporal smoothing in fiscal financing. $L_{t}^{b}$ measures how binding the fiscal solvency constraint is on fiscal policy. $L_{t}^{q}$ measures the tightness of the fiscal solvency constraint on monetary policy by linking $L_{t}^{q}$ to a distributed lag of $L_{t}^{b}$ with weights that decay with $\rho$, the determinant of debt's duration

$$
L_{t}^{q}=\beta(1-\rho) \sum_{k=0}^{\infty} \rho^{k} L_{t-k}^{b}
$$


Maturity structure matters through its implications for fiscal financing. How much monetary policy is constrained by fiscal financing depends on the entire history of shadow prices of the government budget, $L_{t-j}^{b}$, and the degree of history dependence rises with the average maturity of government debt. Restricting attention to only one-period debt, so that $\rho=0$, $L_{t}^{q}=\beta L_{t}^{b}$, eliminates the history dependence and monetary policy is almost as constrained by fiscal solvency as fiscal policy itself is. ${ }^{12}$ At the opposite extreme, consols make $\rho=1$, so $L_{t}^{q} \equiv 0$ and current monetary policy is not constrained, regardless of how binding the government's budget has been in the past, as long as future monetary policies are expected to adjust appropriately. ${ }^{13}$

In general, the price of long bonds can adjust to relax the government's budget constraint. And the term structure relation, (29), connects the price of bonds today to future short-term interest rates. Debt maturity introduces a fresh role for expected monetary policy choices by allowing those expectations to help ensure government solvency. ${ }^{14}$

We examine some special cases that allow us to characterize the optimal equilibrium and the consequent stabilization role of fiscal and monetary policy analytically.

5.1 Only One-Period Bonds Suppose the government issues only one-period bonds, rolled over every period. Then $\rho=0$ and (47) and (29) reduce to

$$
\begin{aligned}
L_{t}^{q} & =\beta L_{t}^{b} \\
\hat{i}_{t}^{M} & =\frac{1}{1-\beta} \hat{i}_{t}
\end{aligned}
$$

Long-term and short-term interest rates are identical, so $L_{t}^{b}$ and $L_{t}^{q}$ covary perfectly. In this case, the expressions for inflation, (43), and the output gap, (44), become

$$
\begin{aligned}
\hat{\pi}_{t} & =-\left(\frac{1-\beta}{\kappa \psi} \frac{\bar{\tau}}{s_{d}}+1\right)\left(L_{t}^{b}-L_{t-1}^{b}\right) \\
\lambda \hat{x}_{t} & =\left[\left(\psi^{-1}-1\right)(1-\beta) \frac{\bar{\tau}}{s_{d}}-\beta \frac{\sigma}{s_{c}}\right] L_{t}^{b}+\frac{\sigma}{s_{c}} L_{t-1}^{b}
\end{aligned}
$$

Condition (50) implies that inflation is proportional to the forecast error in $L_{t}^{b}{ }^{15}$ Because (46) requires there are no forecastable variations in $L_{t}^{b}$, the expectation of inflation is zero, implying perfect smoothing of the price level

$$
E_{t} \hat{\pi}_{t+1}=0 \quad \Rightarrow \quad E_{t} \hat{p}_{t+1}=\hat{p}_{t}
$$

Condition (51) makes the output gap a weighted average of $L_{t}^{b}$ and $L_{t-1}^{b}$. Taking expectations yields

$$
\lambda\left(E_{t} \hat{x}_{t+1}-x_{t}\right)=\frac{\sigma}{s_{c}}\left(L_{t}^{b}-L_{t-1}^{b}\right)
$$

\footnotetext{
${ }^{12}$ This is precisely the exercise that finds the combination of active monetary/passive fiscal policies yields highest welfare [Schmitt-Grohé and Uribe (2007) and Kirsanova and Wren-Lewis (2012)].

${ }^{13}$ Sims (2013) limits attention to this case.

${ }^{14}$ The new Keynesian literature emphasizes the role of expected monetary policy via its influence of the entire future path of ex-ante real interest rates that enter the Euler equation, (21). The role we are discussing for expected monetary policy is in addition to this conventional role.

${ }^{15}$ First-order condition (46) makes $E_{t} L_{t+1}^{b}=L_{t}^{b}$, so the surprise is $L_{t+1}^{b}-E_{t} L_{t+1}^{b}=\Delta L_{t+1}^{b}$.
} 
so the expected change in the output gap next period is proportional to the surprise in the multiplier on government solvency today. The optimal degree of output-gap smoothing varies with $\lambda$, the weight on output in the loss function. The bigger is $\lambda$, the more smoothing of the output gap. Flexible prices are a special case with $\lambda=\infty$ and perfect smoothing of the output gap. Under most calibrations, $\lambda$ is quite small, implying little smoothing of output. But the martingale property of $L_{t}^{b}$ implies smoothing of expected future output gaps after a one-time jump. Taking expectations of (53) yields

$$
\hat{x}_{t} \neq E_{t} \hat{x}_{t+1}=E_{t} \hat{x}_{t+2}=\ldots=E_{t} \hat{x}_{t+k}=\ldots
$$

Taken together, (52) and (54) imply that with only one-period bonds, optimal policies smooth the price level, while using fluctuations in the output gap to absorb innovations in fiscal conditions. The reason is apparent: with no long-term bonds, policy cannot smooth inflation in the future and surprise inflation - and the resulting price dispersion - is far more costly that variations in the output gap; it is optimal to minimize inflation variability and use output as a shock absorber.

In this equilibrium, monetary and fiscal policies follow the rules

$$
\begin{aligned}
& \hat{\tau}_{t}-\hat{\tau}_{t}^{*}=\frac{1}{\kappa \psi}\left(\hat{\pi}_{t}-\kappa \hat{x}_{t}\right) \\
& \hat{i}_{t}-\hat{i}_{t}^{*}=-\frac{\left(\sigma / s_{c}\right)^{2}}{\lambda\left(\frac{1-\beta}{\kappa \psi} \frac{\bar{\tau}}{s_{d}}+1\right)} \hat{\pi}_{t}
\end{aligned}
$$

so monetary policy pins down inflation by offsetting variations in demand-side disturbances and fiscal policy stabilizes the output gap by responding to monetary policy and cost-push disturbances.

5.2 Only Consols Suppose the government issues only consols. With $\rho=1$, (47) and (29) reduce to

$$
\begin{aligned}
& L_{t}^{q}=L_{t-1}^{q}=0 \\
& \hat{i}_{t}^{M}=E_{t} \sum_{k=0}^{\infty} \beta^{k} \hat{i}_{t+k}
\end{aligned}
$$

In the case of consols, the long-term interest rate is determined by the entire path of future short-term interest rates. Fiscal stress that moves long rates need not change short rates contemporaneous, so long as the expected path of short rates satisfies (58). Inflation and output are now

$$
\begin{aligned}
\hat{\pi}_{t} & =-\frac{1-\beta}{\kappa \psi} \frac{\bar{\tau}}{s_{d}}\left(L_{t}^{b}-L_{t-1}^{b}\right)-L_{t}^{b} \\
\lambda \hat{x}_{t} & =\left(\psi^{-1}-1\right)(1-\beta) \frac{\bar{\tau}}{s_{d}} L_{t}^{b}
\end{aligned}
$$

Combining (59) and (60) yields

$$
\hat{\pi}_{t}+\frac{\lambda}{\kappa(1-\psi)}\left(\hat{x}_{t}-\hat{x}_{t-1}\right)+\frac{\lambda}{\left(\psi^{-1}-1\right)(1-\beta) \frac{\bar{\tau}}{s_{d}}} \hat{x}_{t}=0
$$


an expression that generalizes the "flexible target criterion" found in conventional optimal monetary policy exercises in new Keynesian models. ${ }^{16}$

Condition (60) makes the output gap proportional to $L_{t}^{b}$. The martingale property of $L_{t}^{b}$ makes the output gap also a martingale, so the gap is perfectly smoothed

$$
E_{t} \hat{x}_{t+1}=\hat{x}_{t}
$$

Taking expectations of (59) and combining with (60), we have

$$
E_{t} \hat{\pi}_{t+1}-\hat{\pi}_{t}=\frac{\lambda}{\kappa(1-\psi)}\left(\hat{x}_{t}-\hat{x}_{t-1}\right)
$$

Condition (63) implies that the expected change in the inflation next period is proportional to the forecasting error of $\hat{x}_{t}$. The degree of inflation smoothing changes inversely with $\lambda$, the weight on output in the loss function, while the degree of inflation smoothing varies proportionally with $\kappa$, the slope of the Phillips curve.

Combining (62) and (63), we draw opposite conclusions about the assignment between inflation and output gap to the case of only one-period bonds. With only consols, intertemporal smoothing in the shadow price of the government budget constraint, $L_{t}^{b}$, smoothes the output gap, relying on fluctuations in inflation to absorb innovations in fiscal conditions. To understand this, refer to the government solvency condition

$$
\hat{b}_{t-1}^{M}+\beta \rho \hat{Q}_{t}^{M}-\hat{\pi}_{t}=(1-\beta) E_{t} \sum_{k=0}^{\infty} \beta^{k}\left(\hat{r}_{t, t+k}+\hat{s}_{t+k}\right)
$$

where $\hat{r}_{t, t+k}$ is the log-linearized real discount rate. Consols introduce the possibility that the bond price $\hat{Q}_{t}^{M}$ can behave as a fiscal shock absorber: bad news about future surpluses can reduce the value of outstanding bonds, leaving the real discount rate unaffected. A constant real discount rate smoothes the output gap, which explains the absence of forecastable variations in the output gap. Variations in the bond price $\hat{Q}_{t}^{M}$ correspond to adjustments in future inflation. The longer the duration of debt-higher $\rho$ - the less is the required change in bond prices and future inflation for a given change in the present-value of surpluses. Although with consols it is optimal to allow surprise inflation and deflation to absorb shocks, the expectation of inflation is stabilized after a one-time jump

$$
\hat{\pi}_{t} \neq E_{t} \hat{\pi}_{t+1}=E_{t} \hat{\pi}_{t+2}=\ldots=E_{t} \hat{\pi}_{t+k}=\ldots
$$

Optimal monetary and fiscal policy obey

$$
\begin{aligned}
& \hat{\tau}_{t}-\hat{\tau}_{t}^{*}=\frac{1}{\kappa \psi}\left(\hat{\pi}_{t}-\beta E_{t} \hat{\pi}_{t+1}-\kappa \hat{x}_{t}\right) \\
& \hat{i}_{t}-\hat{i}_{t}^{*}=E_{t} \hat{\pi}_{t+1}=-\frac{\lambda}{(1 / \psi-1)(1-\beta) \frac{\bar{\tau}}{s_{d}}} \hat{x}_{t}
\end{aligned}
$$

\footnotetext{
${ }^{16}$ Notice that as $\psi \rightarrow 0$, which occurs as the steady state distorting tax rate approaches $0, L_{t}^{b} \rightarrow 0$ and (61) approaches the conventional flexible target criterion with lump-sum taxes $\hat{\pi}_{t}+\frac{\lambda}{\kappa}\left(\hat{x}_{t}-\hat{x}_{t-1}\right)=0$ so that the optimal inflation rate should vary with both the the rate of change in the output gap and the level of the gap [see Woodford (2011) and references therein].
} 
Monetary policy pins down expected inflation, but not actual inflation. Expected inflation determines how much fiscal stress is absorbed through changes in long-term bond prices and with more adjustment occurring through inflation, the output gap is better stabilized. Fiscal policy determines inflation by responding to monetary policy and cost-push side disturbances.

5.3 General Case We briefly consider intermediate value for the average duration of debt, $0<\rho<1$. Rewrite (43) and (44) using the lag-operator notation, $\mathbb{L}^{j} x_{t} \equiv x_{t-j}$

$$
\begin{aligned}
\hat{\pi}_{t} & =-\frac{(1-\beta) \frac{\bar{\tau}}{s_{d}}}{\kappa \psi}(1-\mathbb{L}) L_{t}^{b}-(1-\mathbb{L})(1-\rho \mathbb{L})^{-1} L_{t}^{b} \\
\lambda \hat{x}_{t} & =\left(\psi^{-1}-1\right)(1-\beta) \frac{\bar{\tau}}{s_{d}} L_{t}^{b}-\frac{\sigma \beta}{s_{c}}(1-\rho)\left(1-\beta^{-1} \mathbb{L}\right)(1-\rho \mathbb{L})^{-1} L_{t}^{b}
\end{aligned}
$$

The optimality condition for debt that requires $L_{t}^{b}$ to be a martingale may be written as

$$
(1-\mathbb{B}) E_{t-1} L_{t}^{b}=0
$$

where $\mathbb{B}$ is the backshift operator, defined as $\mathbb{B}^{-j} E_{t} \xi_{t} \equiv E_{t} \xi_{t+j}$.

Taking expectations of (68) and (69), and applying (70), we obtain a general expression of k-step ahead expectations of inflation and output gap

$$
\begin{aligned}
& E_{t} \hat{\pi}_{t+k}=\rho^{k} \hat{\pi}_{t}+\rho^{k} \alpha_{\pi}\left(L_{t}^{b}-L_{t-1}^{b}\right) \\
& E_{t} \hat{x}_{t+k}=\rho^{k} \hat{x}_{t}+\left(1-\rho^{k}\right) \alpha_{x} L_{t}^{b}
\end{aligned}
$$

Equations (71) and (72) neatly encapsulate the policy problem. The first terms on the right stem from the welfare improvements that arise from smoothing. That both terms involve $\rho^{k}$ means that longer maturity debt helps to smooth both inflation and output. The second terms bring in the government solvency dimension of optimal policy through the Lagrange multipliers. It captures the tradeoff between relying on variations in inflation to hedge against fiscal stress versus variations in output to absorb shocks. The average maturity has opposite effect on the two variables. As maturity extends, changes in the state of government solvency are permitted to affect future inflation more strongly, whereas the output gap becomes less responsive. In other words, as maturity extend, it is optimal to tradeoff inflation for output stabilization. For any maturities short of perpetuities, $0 \leq \rho<1$, as the forecast horizon extends, $k \rightarrow \infty$, expected inflation converges to zero whereas the expected output gap converges to $\alpha_{x} L_{t}^{b}$. In these cases, inflation is well anchored on zero, but the output gap's "anchor" varies with the state at $t$.

\section{Calibration}

We turn to numerical results from the model calibrated to U.S. data in order to focus on a set of implications that may apply to an actual economy.

Table 2 reports a calibration to U.S. time series. We take the model's frequency to be quarterly and adopt some parameter values from Benigno and Woodford (2004), including 
$\beta=0.99, \theta=0.66$ and $\epsilon=10$; we set $\varphi=\sigma=0.5$, implying a Frisch elasticity and an intertemporal elasticity of substitution of 2.0, both reasonable empirical values. Quarterly U.S. data from 1948Q1 to 2013Q1 underlie the values of $s_{b}, s_{g}, s_{z}$ and are used to estimate autoregressive processes for $A_{t}, G_{t}, \tau_{t}, Z_{t}$ shocks. ${ }^{17}$ Following Galí et al. (2007), the wage markup shock is calibrated as an $\mathrm{AR}(1)$ process with persistence of 0.95 and standard deviation of 0.054 . Table 2's calibration makes the relative weight on output-gap stabilization equal to $\lambda=0.0033$, slightly higher than the value used in Benigno and Woodford (2007) $(\lambda=0.0024) .^{18}$

\begin{tabular}{|c|c|c|}
\hline \hline Parameter & Definition & Value \\
\hline$\beta$ & discount rate & 0.99 \\
$\sigma$ & the inverse of intertemporal elasticity of substitution & 0.50 \\
$\varphi$ & the inverse of Frisch elasticity of labor supply & 0.50 \\
$\theta$ & the fraction of firms cannot adjust their prices & 0.66 \\
$\epsilon$ & intratemporal elasticity of substitution across consumption goods & 10 \\
$s_{c}$ & steady state consumption to gdp ratio & 0.87 \\
$s_{z}$ & steady state government transfer payment to gdp ratio & 0.09 \\
$s_{g}$ & steady state government spending-gdp ratio & 0.13 \\
$s_{b}$ & steady state debt-gdp ratio & $0.49 \times 4$ \\
$\bar{\tau}$ & steady state tax rate & 0.24 \\
$\rho_{a}$ & autoregressive coefficient of tech shock & 0.786 \\
$\rho_{g}$ & autoregressive coefficient of government spending shock & 0.886 \\
$\rho_{\tau}$ & autoregressive coefficient of tax rate shock & 0.782 \\
$\rho_{z}$ & autoregressive coefficient of wage markup shock & 0.56 \\
$\rho_{w}$ & standard deviation of innovation to tech shock & 0.95 \\
$\sigma_{e}^{a}$ & standard deviation of innovation to government spending shock & 0.008 \\
$\sigma_{e}^{g}$ & standard deviation of innovation to tax rate shock & 0.029 \\
$\sigma_{e}^{\tau}$ & standard deviation of innovation to transfer payment shock & 0.047 \\
$\sigma_{e}^{z}$ & standard deviation of innovation to wage markup shock & 0.054 \\
$\sigma_{e}^{w}$ &
\end{tabular}

Table 2: Calibration to U.S. Data

\section{Separating the Impacts of Maturity}

To fully understand the impacts of debt maturity on the tradeoffs between inflation and output stabilization, we rewrite the government intertemporal equilibrium condition (30) in

\footnotetext{
${ }^{17}$ Appendix $\mathrm{H}$ provides details.

${ }^{18}$ Benigno and Woodford's calibration of $\sigma=0.16$ largely explains the difference in the values of $\lambda$.
} 
terms of only inflation and the output gap

$$
\begin{aligned}
\hat{b}_{t-1}^{M}+F_{t}= & \underbrace{\hat{\pi}_{t}+(1-\beta) \frac{b_{\tau}}{\kappa \psi} \hat{\pi}_{t}}_{\text {surprise inflation }}+\underbrace{E_{t} \sum_{k=1}^{\infty}(\beta \rho)^{k} \hat{\pi}_{t+k}}_{\text {future inflation }} \\
& -\underbrace{(1-\beta) b_{\tau}\left(\frac{1}{\psi}-1\right) E_{t} \sum_{k=0}^{\infty} \beta^{k} \hat{x}_{t+k}}_{\text {future output }}-\underbrace{E_{t} \sum_{k=0}^{\infty}\left[(1-\beta) \beta^{k}-(1-\beta \rho)(\beta \rho)^{k}\right] \frac{\sigma}{s_{c}}\left(\hat{x}_{t+k}-\hat{x}_{t}\right)}_{\text {real interest rate }}
\end{aligned}
$$

Given the fiscal stress, $\hat{b}_{t-1}^{M}+F_{t}$, (73) completely summarizes feasible paths of current and expected inflation and output gaps. To absorb exogenous disturbances to $F_{t}$, some combination of paths of inflation and output must adjust. This equation underscores the inherent symmetry between monetary and fiscal policy: interactions between the two policies determine the reliance on variations in output gaps versus inflation rates.

Average duration of government bonds affects the optimal equilibrium through three channels. First, it affects overall fiscal stress, $F_{t}$, given the processes of exogenous disturbances. Second, it affects the allocation of inflation rates over time. Third, it affects real allocations through changing real discount rates.

$7.1 \rho$ 's ImPACT ON $F_{t} \quad F_{t}$, a composite measure of fiscal stress, summarizes the factors in our model that prevent complete stabilization of inflation and the welfare-relevant output gap. $F_{t}$ may be expressed in terms of the four fundamental shocks

$$
F_{t}=F_{A} \hat{A}_{t}+F_{G} \hat{G}_{t}+F_{Z} \hat{Z}_{t}+F_{W} \hat{\mu}_{t}^{W}
$$

where

$$
F_{x}=\left(1-\beta \rho_{x}\right)^{-1}\left[f_{x}+(1-\beta) \frac{\bar{\tau}}{s_{d}} \frac{1}{\kappa \psi} u_{x}+\beta \frac{\sigma}{s_{c}} v_{x}\right]-\beta \rho\left(1-\beta \rho \rho_{x}\right)^{-1} \frac{\sigma}{s_{c}} v_{x}, \quad x=A, G, Z, W
$$

The average maturity of bonds affects the amount of fiscal stress imposed on equilibrium through the weights attached to each fundamental shock. Figure 1 plots the feedback coefficients for each of the fundamental shocks, as defined in (74). $F_{A}$ is negative for all average bond durations, while $F_{G}, F_{Z}, F_{W}$ are positive. A positive innovation to technology helps relieve fiscal stress by raising tax revenues, improving the tension between inflation and the output gap. Positive innovations to wage markups, government spending or transfer payments, in contrast, aggravate fiscal stress and make it more difficult to stabilize inflation and the output gap contemporaneously. The impacts of technology, wage markups and government spending shocks abate as the average maturity of bonds grows longer, while the impact of government transfers becomes stronger with longer-term bonds. Finally, the impact of each fundamental shock on fiscal stress is ranked $\left|F_{W}\right|>\left|F_{A}\right|>\left|F_{G}\right|>\left|F_{Z}\right|$. Wage markups and technology shocks affect $F_{t}$ more strongly than do government spending and transfers shocks. The complicated heterogeneity among different shocks in affecting the overall fiscal stress makes some of our results sensitive to the calibration of the four fundamental shocks. 

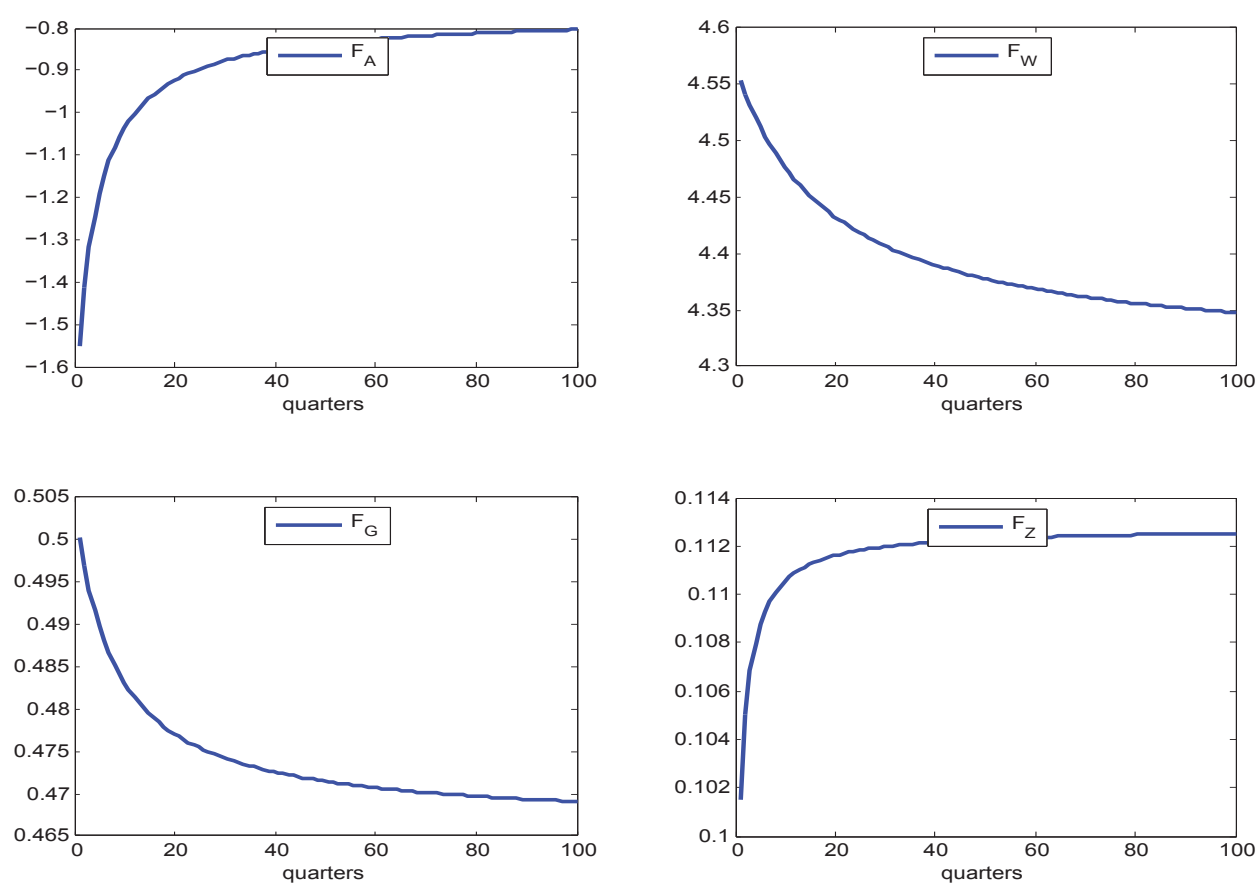

Figure 1: The mapping from fundamental shocks $\hat{A}_{t}$ (technology), $\hat{\mu}_{t}^{W}$ (wage markup), $\hat{G}_{t}$ (government purchases), $\hat{Z}_{t}$ (government transfers) to fiscal stress, $F_{t}$, in (74).

We turn now to study how the changes in average maturity of government bonds affects the tradeoff between stabilizing inflation and the output gap. To distinguish the average maturity structure's impact on inflation and the output gap, we consider two polar suboptimal cases: (i) complete stabilization of the output gap, depending only on inflation as a shock absorber and (ii) complete stabilization of inflation, using only the output gap as a shock absorber.

7.2 Inflation Smoothing Complete output stabilization sets $\hat{x}_{t} \equiv 0$ and uses current and future inflation to fully absorb innovations to $\hat{b}_{t-1}^{M}+F_{t}$. This polar case eliminates the effect of maturity on tax smoothing and to focus on how alternative maturity structures dynamically allocate inflation. Constraint (73) becomes

$$
\hat{b}_{t-1}^{M}+F_{t}=\underbrace{\hat{\pi}_{t}+(1-\beta) \frac{b_{\tau}}{\kappa \psi} \hat{\pi}_{t}}_{\text {surprise inflation }}+\underbrace{E_{t} \sum_{k=1}^{\infty}(\beta \rho)^{k} \hat{\pi}_{t+k}}_{\text {bond prices }}
$$

The term $(1-\beta) \frac{b_{\tau}}{\kappa \psi} \hat{\pi}_{t}$ stems from the effects of distorting taxes on inflation at time $t$. The Phillips curve

$$
\hat{\pi}_{t}=E_{t} \sum_{k=0}^{\infty} \beta^{k}\left[\kappa \hat{x}_{t+k}+\kappa \psi\left(\hat{\tau}_{t+k}-\hat{\tau}_{t+k}^{*}\right)\right]
$$

implies that increasing future tax rates decreases the path of output or increases current inflation. When output is fully stabilized, inflation must rise. This inflationary effect of fiscal 
policy is absent from Cochrane (2001) and Sims (2013) and arises here from distortionary taxes.

Figure 2 plots responses to a unit innovation in fiscal stress, $F_{t}$, under the two sub-optimal cases and under fully optimal policies. Panel I imposes output stabilization, $x_{t} \equiv 0$. With only one-period bonds (solid lines), inflation jumps immediately and then returns to zero, since intertemporal smoothing of inflation is unavailable. $L_{t}^{q}$ and $L_{t}^{b}$ deviate substantially from zero, implying monetary and fiscal policy is constrained most tightly. With 5-year bonds (dashed lines), inflation reacts less aggressively in the first period, and then gradually goes back to zero. The presence of long-term bonds allows the government to tradeoff inflation today for inflation in the future. $L_{t}^{q}$ doesn't deviate in the first period but displays a pattern of gradual deviations, implying that monetary policy today could be freed from the fiscal constraint if future monetary policies adjust appropriately. Finally, with consols (dotted-dashed lines), the immediate response of inflation is the smallest, with future inflation permanently, but only slightly, higher. ${ }^{19}$

The pattern of impulse responses could be illustrated by considering the following optimal problem

$$
\begin{gathered}
\min \frac{1}{2} E_{0} \sum_{t=0}^{\infty} \beta^{t} q_{\pi} \hat{\pi}_{t}^{2} \\
\text { s.t. } \quad \hat{b}_{-1}^{M}+F_{0}=b_{\pi} \hat{\pi}_{0}+E_{0} \sum_{t=1}^{\infty}(\beta \rho)^{t} \hat{\pi}_{t}
\end{gathered}
$$

where $b_{\pi}=1+(1-\beta) \frac{b_{\tau}}{\kappa \psi}$. The first-order condition yields

$$
E_{0} \hat{\pi}_{1}=\rho \frac{\hat{\pi}_{0}}{b_{\pi}} \quad \text { and } \quad E_{0} \hat{\pi}_{t+1}=\rho E_{0} \hat{\pi}_{t}, \quad t \geq 1
$$

If $\rho=0$, we have $E_{0} \hat{\pi}_{t}=0(t \geq 1)$, inflation is expected to remain at zero after period 0 . If $\rho=1$, we have $E_{0} \hat{\pi}_{t}=\frac{\hat{\pi}_{0}}{b_{\pi}}(t \geq 1)$, inflation is expected to deviate permanently by a constant amount after period 0 . If $0<\rho<1$, inflation is expected to deviate by $\frac{\rho}{b_{\pi}} \hat{\pi}_{0}$ at period 1 and then decay at rate of $\rho$ afterwards. The immediate response of inflation at period 0 is given by

$$
\hat{\pi}_{0}=\frac{\hat{b}_{-1}^{M}+F_{0}}{b_{\pi}+b_{\pi}^{-1}\left[\left(1-\beta \rho^{2}\right)^{-1}-1\right]}
$$

$\hat{\pi}_{0}$ is decreasing in $\rho$. The longer the average maturity, the milder and more persistent the inflation.

\footnotetext{
${ }^{19}$ This result differs slightly from Sims (2013), who finds complete smoothing of inflation with only consols. Differences stem from Sims's use of lump-sum taxes, which do not have the direct inflationary effects that distortionary taxes produce.
} 
Panel I: Responses to One Unit Increase in $F_{t}$ when only using variations in inflation to adjust
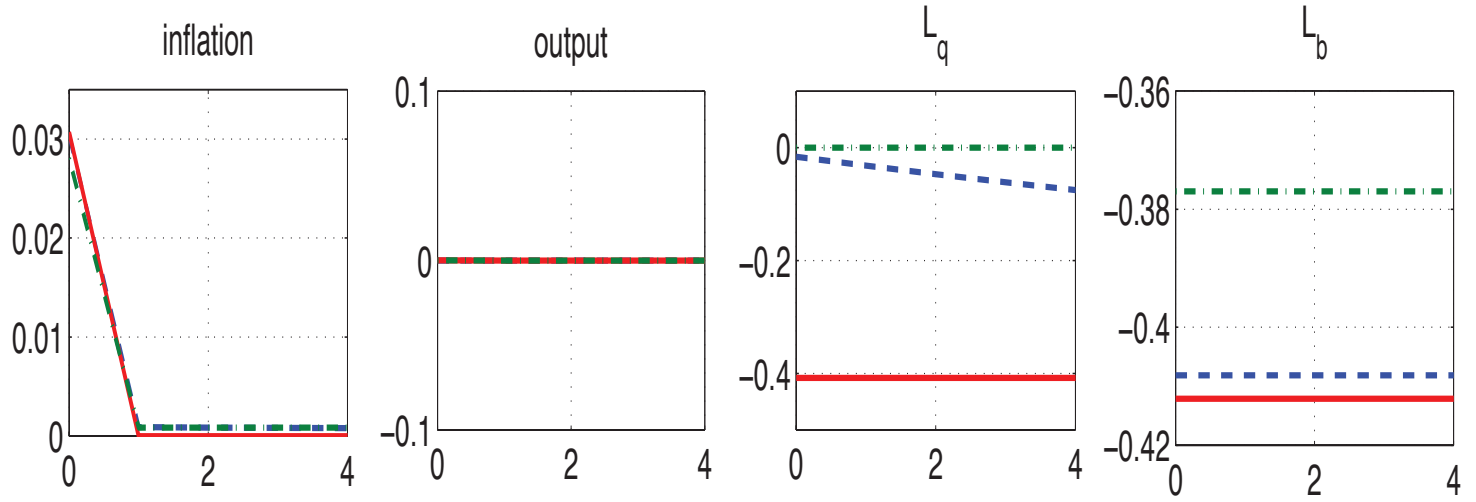

Panel II: Responses to One Unit Increase in $\mathrm{F}_{t}$ when only using variations in output to adjust
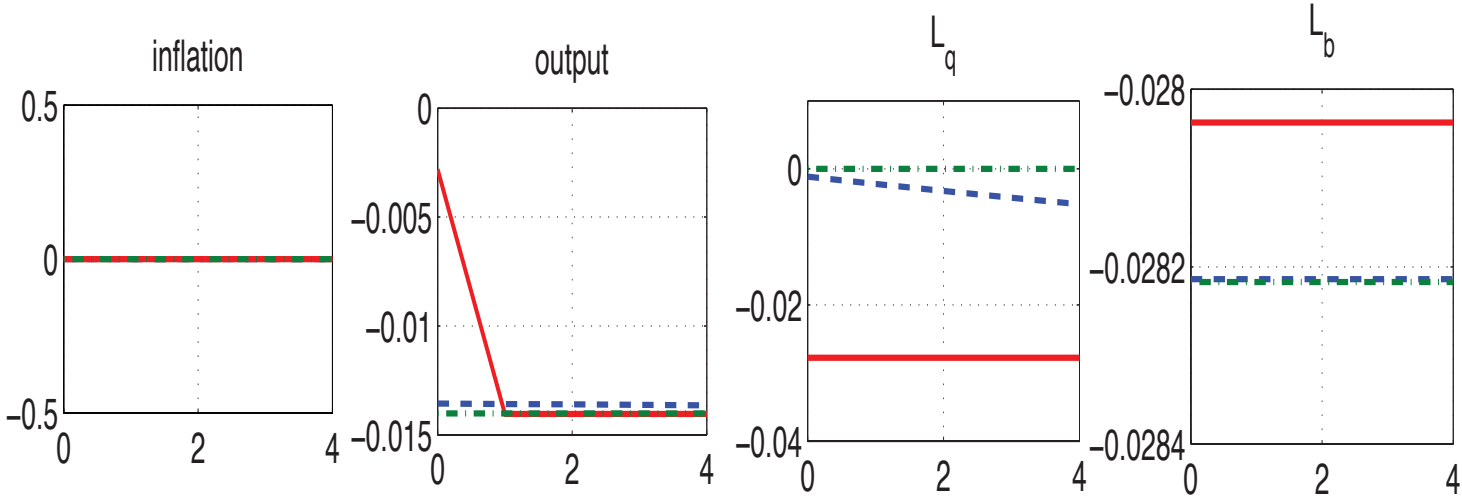

Panel III: Responses to One Unit Increase in $\mathrm{F}_{t}$ when using variations in both inflation and output to adjust
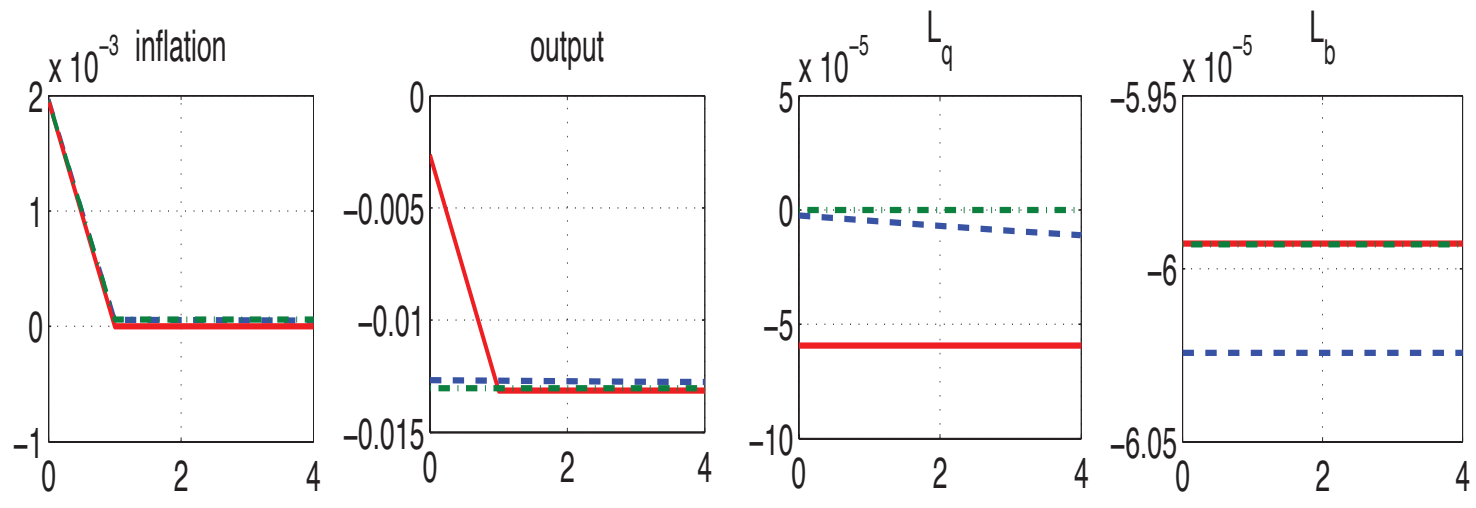

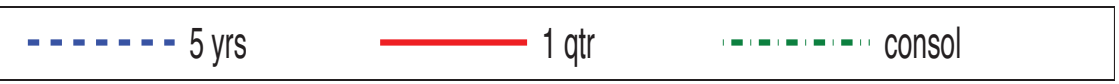

Figure 2: Responses to a one unit innovation in fiscal stress, $F_{t}$ 
7.3 Output Smoothing Suppose now that $\hat{\pi}_{t} \equiv 0$ so that adjustments in current and future output gaps must absorb innovations to $\hat{b}_{t-1}^{M}+F_{t}$. Then (73) becomes

$$
\hat{b}_{t-1}^{M}+F_{t}=\underbrace{-(1-\beta)\left(\frac{b_{\tau}}{\psi}-b_{x}\right) E_{t} \sum_{k=0}^{\infty} \beta^{k} \hat{x}_{t+k}}_{\text {tax revenues }}+\underbrace{\frac{\sigma}{s_{c}}(1-\beta \rho) E_{t} \sum_{k=0}^{\infty}(\beta \rho)^{k} \hat{x}_{t+k}}_{\text {bond price }}
$$

Changes in output help to satisfy the solvency condition by directly affecting tax revenues and by the impacts of output on real returns to the bond portfolio. These two parts produce opposite effects. Consider an exogenous increase in fiscal stress. Relying on tax revenues to fully offset this disturbance requires increasing the tax rate. But by the Phillips curve

$$
\hat{\pi}_{t}=E_{t} \sum_{k=0}^{\infty} \beta^{k}\left[\kappa \hat{x}_{t+k}+\kappa \psi\left(\hat{\tau}_{t+k}-\hat{\tau}_{t+k}^{*}\right)\right]
$$

when $\pi_{t} \equiv 0$, a higher tax rate must reduce output. This is the negative effect in the first term. Lower output generates a second effect by increasing real returns on long-term bonds. This positive effect is captured by the second term. The second effect is usually omitted by assuming a constant or exogenous real discount rate as in Cochrane (2001) and Sims (2013). In our model, if we set $\sigma=0$, then utility is linear and the real rate is constant. This mutes the second channel and we obtain a smoothing of the output gap $E_{0} \hat{x}_{t+1}=\hat{E}_{0} x_{t}$ as in Sims (2013).

Panel II plots responses to higher fiscal stress when inflation is completely stable. With only one-period bonds, the output gap first deviates by a small amount at time 0 and then continues to jump to a constant level. $L_{t}^{q}$ and $L_{t}^{b}$ both deviate from zero, but by a much smaller number than in panel I, implying that adjusting output gaps is less costly than adjusting inflation. With 5-year bonds, output drops sharply in the first period and then gradually converges to the same level as with one-period bonds. With consols, the output gap is perfectly smoothed after a one-time jump in the first period. Long-term bonds allow the government to smooth the output gap. To better understand this, we consider the following optimal problem:

$$
\begin{gathered}
\min \frac{1}{2} E_{0} \sum_{t=0}^{\infty} \beta^{t} q_{x} \hat{x}_{t}^{2} \\
\text { s.t. } \hat{b}_{-1}^{M}+F_{0}=-(1-\beta)\left(\frac{b_{\tau}}{\psi}-b_{x}\right) E_{0} \sum_{t=0}^{\infty} \beta^{t} \hat{x}_{t}+\frac{\sigma}{s_{c}}(1-\beta \rho) E_{0} \sum_{t=0}^{\infty}(\beta \rho)^{t} \hat{x}_{t}
\end{gathered}
$$

The first-order condition yields

$$
E_{0} \hat{x}_{t}=l_{t}^{x} \hat{x}_{0}, \quad t \geq 1, \quad \text { where } l_{t}^{x} \equiv \frac{\frac{\sigma}{s_{c}}(1-\beta \rho) \rho^{t}-(1-\beta)\left(\frac{b_{\tau}}{\psi}-b_{x}\right)}{\frac{\sigma}{s_{c}}(1-\beta \rho)-(1-\beta)\left(\frac{b_{\tau}}{\psi}-b_{x}\right)}
$$

Unlike inflation, which is expected to decay at a constant rate $\rho$, the output gap is expected to deviate at a time-varying rate $l_{t}^{x}$. When $\rho=0, E_{0} \hat{x}_{t}=\frac{-(1-\beta)\left(\frac{b_{\tau}}{\psi}-b_{x}\right)}{\frac{\sigma}{s_{c}}-(1-\beta)\left(\frac{b_{\tau}}{\psi}-b_{x}\right)} \hat{x}_{0}(t \geq 1)$, there is a 
permanent constant deviation of the output gap; when $\rho=1, E_{0} \hat{x}_{t}=x_{0}(t \geq 1)$, the output gap is expected to be perfectly smoothed. When $0<\rho<1, l_{t}^{x}$ is generally time-varying. Figure 3 plots $l_{t}^{x}$ for $t=1,3,10$ at all maturities. We observe that when the average maturity is relatively short (under 5 years), $l_{t}^{x}$ is time-varying and the output gap is expected to deviate further and further as time grows. The output gap is expected to deviate the most when the average maturity is about 2 quarters. However, when the average maturity is long enough (over 5 years), $l_{t}^{x}$ is almost 1 for all periods, implying perfect smoothing of the output gap. Short-to-medium maturities increase fluctuations in the output gap and long-term bonds help to smooth the output gap only when the average maturity is relatively long.

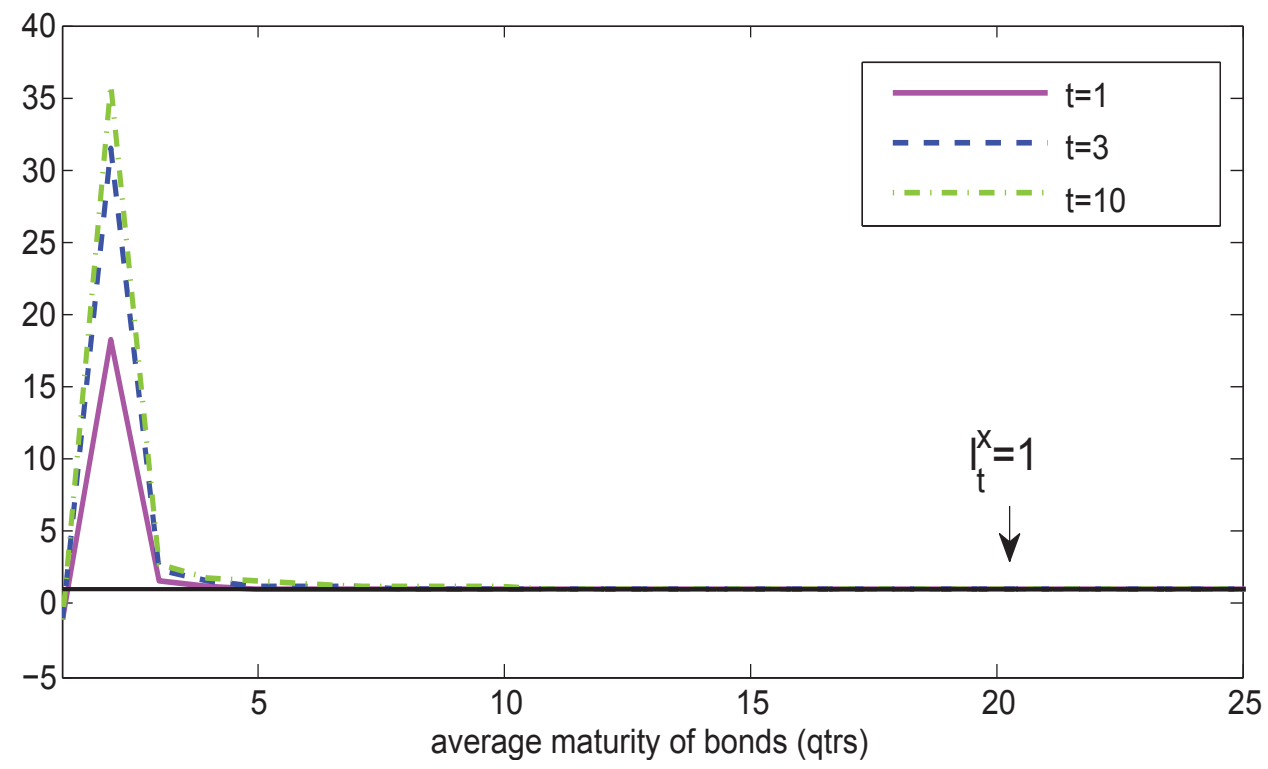

Figure 3: The rate of deviation $l_{t}^{x}$

\section{Optimal Choice Between Inflation and Output Stabilization}

This section brings inflation smoothing together with output-gap smoothing to examine the joint determination of output and inflation in the presence of distortionary taxes and sticky prices. With distortionary taxes, variations in tax rates lead to distortions in real allocations and generates welfare loss; with sticky prices, unexpected variations in inflation create distortions in the allocation of resources and reduces welfare. If there is a disturbance to the government budget, monetary and fiscal policy face a tradeoff between stabilizing inflation and stabilizing the output gap. Panel III in figure 2 plots the impulse responses under the fully optimal solution to a unit increase in fiscal stress. Responses are much like a combination of responses in panels I and II. Both inflation and output adjust to absorb disturbances to $F_{t}$.

The optimum problem minimizes the loss function

$$
L=\frac{1}{2} E_{0} \sum_{t=0}^{\infty} \beta^{t}\left(q_{\pi} \hat{\pi}_{t}^{2}+q_{x} \hat{x}_{t}^{2}\right)
$$


subject to the constraint given by (73)

$$
\begin{aligned}
\hat{b}_{t-1}^{M}+F_{t}= & \hat{\pi}_{t}+(1-\beta) \frac{b_{\tau}}{\kappa \psi} \hat{\pi}_{t}+E_{t} \sum_{k=1}^{\infty}(\beta \rho)^{k} \hat{\pi}_{t+k} \\
& -(1-\beta) b_{\tau}\left(\frac{1}{\psi}-1\right) E_{t} \sum_{k=0}^{\infty} \beta^{k} \hat{x}_{t+k}-E_{t} \sum_{k=0}^{\infty}\left[(1-\beta) \beta^{k}-(1-\beta \rho)(\beta \rho)^{k}\right] \frac{\sigma}{s_{c}}\left(\hat{x}_{t+k}-\hat{x}_{t}\right)
\end{aligned}
$$

Solving this problem yields the optimal equilibrium paths of inflation and the output gap. Defining $L_{\pi}=\frac{1}{2} E_{0} \sum_{t=0}^{\infty} \beta^{t} q_{\pi} \pi_{t}^{2}$ and $L_{x}=\frac{1}{2} E_{0} \sum_{t=0}^{\infty} \beta^{t} q_{x} x_{t}^{2}$, we can decompose the loss function into two parts

$$
L=L_{\pi}+L_{x}
$$

where $L_{\pi}$ measures the welfare loss from fluctuations in inflation (expected present value of welfare losses associated with inflation variability) and $L_{x}$ measures the welfare loss from fluctuations in output (expected present value of welfare losses associated with output-gap variation).$^{20}$ For each value of average maturity $\rho$, we compute the value of loss function $L$ and the optimal mix of $L_{\pi}$ and $L_{x}$, which we plot in the two upper panels of figure 4 .

The loss function is hump-shaped in $\rho$ : when the average maturity increases from 1 to 2 quarters, the loss $L$, expressed in terms of the equivalent permanent output decline, increases by 1 percentage point; after 2 quarters, the loss $L$ decreases monotonically in $\rho$. To see why the loss function is hump-shaped, return to figure 3. When the average maturity is relatively short, the output gap tends to be volatile, increasing welfare losses. Our conclusion is consistent with Eusepi and Preston (2013), who find that medium average maturity is most harmful for stability.

In the right panel of figure 4 , the present value of welfare losses for inflation variation, $L_{\pi}$, is plotted along the horizontal axis and the losses from output fluctuations, $L_{x}$, is plotted along the vertical axis. $L=L_{\pi}+L_{x}$ represents negatively sloped isoloss lines. Isoloss lines closer to the origin correspond to lower loss. The optimal mix of $L_{\pi}$ and $L_{x}$ is plotted as shaded circles as $\rho$ varies. For all maturities, $L_{x}$ is almost 10 times larger than $L_{\pi}$, implying that inflation is better stabilized than is the output gap. Other dynamic patterns emerge. As the average maturity of bonds moves from 1 to 2 quarters, both $L_{\pi}$ and $L_{x}$ increase, consistent with the increase in the overall loss function. As average maturity moves from 2 quarters toward consols, $L_{x}$ decreases and $L_{\pi}$ generally increases: stabilization of the output gap becomes more desirable from a welfare perspective as the average maturity of debt extends.

To shed light on the relative importance of inflation versus output variation as sources of welfare losses, the lower panel of figure 4 plots the ratios $\frac{L_{\pi}}{L}$ and $\frac{L_{x}}{L}$ for different average maturities. When the average maturity is 1 quarter, $L_{\pi}$ accounts for $6.7 \%$ of overall loss while $L_{x}$ accounts for $93.3 \%$ of overall loss. As the average maturity gets longer, $L_{\pi}$ accounts for a larger fraction of the welfare losses. In the case of consols, $L_{\pi}$ accounts for $10 \%$ of overall loss while $L_{x}$ accounts for $90 \%$. There is a strictly increasing trend in depending on fluctuations

\footnotetext{
${ }^{20}$ We define $L_{x}$ and $L_{\pi}$ using second moment of $\hat{\pi}_{t}$ and $\hat{x}_{t}$ intead of computing uncontional variance of $\hat{\pi}_{t}$ and $\hat{x}_{t}$, because with $\rho>0, \hat{x}_{t}$ and $\hat{\pi}_{t}$ might have unit root, and the variances are time-varying. This is analogous to Taylor's (1979) policy tradeoff curves.
} 

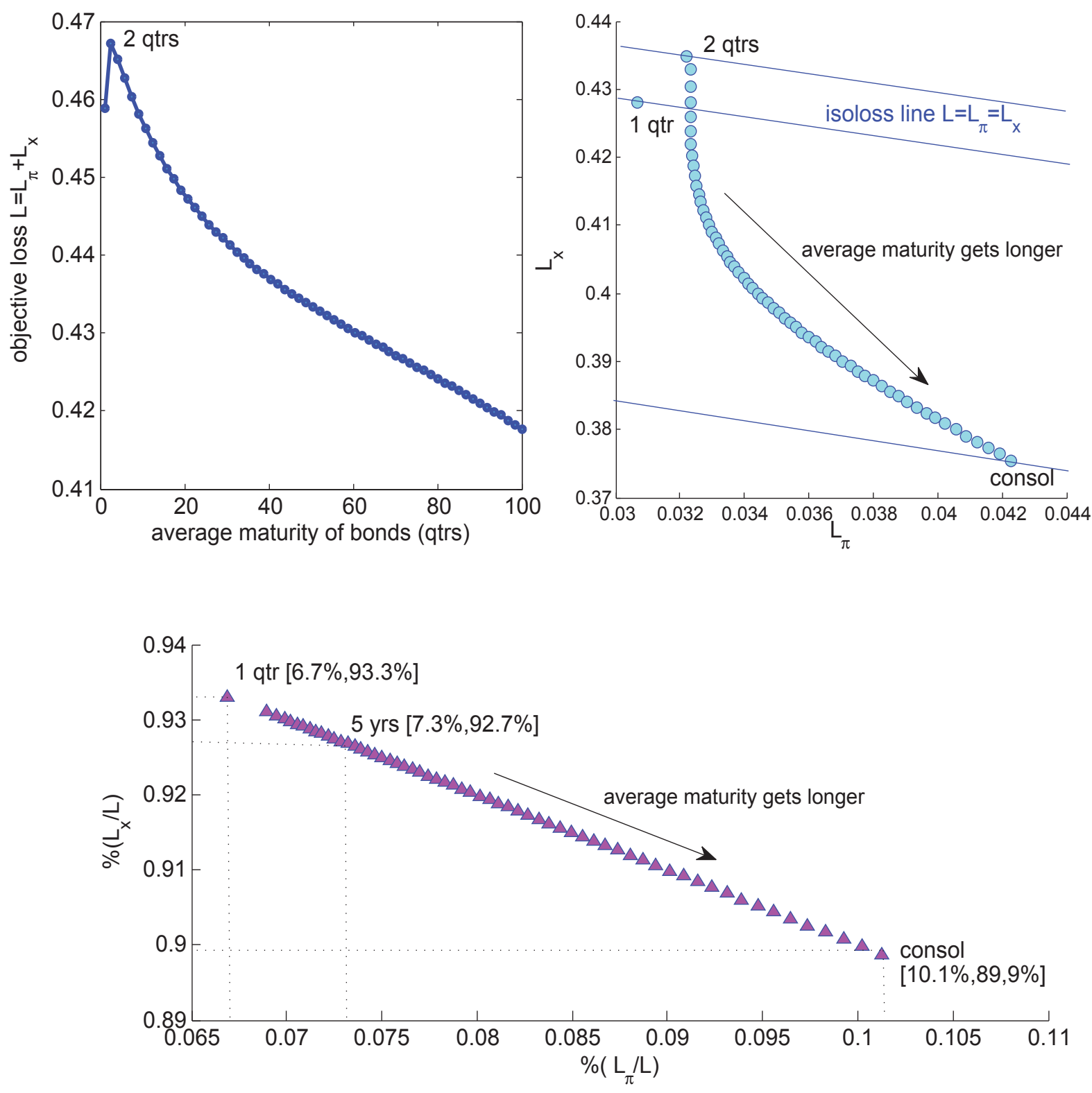

Figure 4: Welfare losses - total and due to inflation and output variability - as a function of average duration of government debt, expressed as percentages of steady state consumption

in inflation to hedge against exogenous shocks when average maturity of government debt extends.

\section{Fiscal Financing}

Sims (2013) emphasizes the role of surprise inflation as a "fiscal cushion" that can reduce the reliance on distorting sources of revenues. One way to quantify the fiscal cushion is to use the government's solvency condition to account for the sources of fiscal financing - including current and future inflation-following an innovation in the present value of fiscal stress $F_{t}$. The government solvency condition may be written as 


$$
\begin{aligned}
\hat{b}_{t-1}^{M}+F_{t}= & \underbrace{\hat{\pi}_{t}+(1-\beta) \frac{b_{\tau}}{\kappa \psi} \hat{\pi}_{t}}_{\text {surprise inflation }}+\underbrace{E_{t} \sum_{k=1}^{\infty}(\beta \rho)^{k} \hat{\pi}_{t+k}}_{\text {future inflation }} \\
& -\underbrace{(1-\beta) b_{\tau}\left(\psi^{-1}-1\right) E_{t} \sum_{k=0}^{\infty} \beta^{k} \hat{x}_{t+k}}_{\text {future output }}-\underbrace{E_{t} \sum_{k=0}^{\infty}\left[(1-\beta) \beta^{k}-(1-\beta \rho)(\beta \rho)^{k}\right] \frac{\sigma}{s_{c}}\left(\hat{x}_{t+k}-\hat{x}_{t}\right)}_{\text {real interest rate }}
\end{aligned}
$$

Fiscal financing underscores the inherent symmetry between monetary and fiscal policy: interactions between the two policies determine the reliance on tax revenues, which decreases output, versus current and future inflation.

Fiscal Financing Decomposition
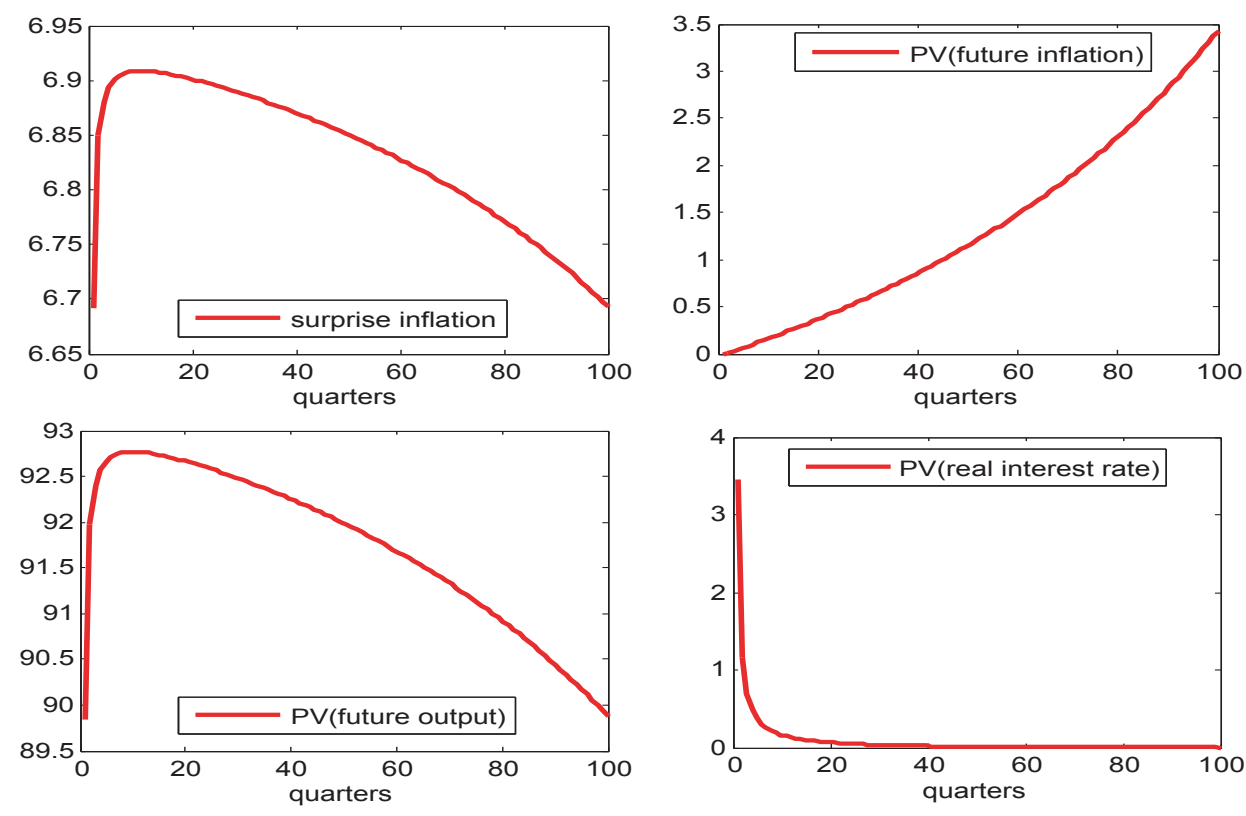

Figure 5: Fraction of fiscal stress innovation financed by each of the four components in (81), as a function of average duration of government debt

Figure 5 plots the financing decomposition for one unit increase of fundamental shock as a function of the average duration of government bonds for the calibration to U.S. data in table 2. The pattern of this decomposition is robust in that it does not depend on the nature of shocks. In figure 5 the vast majority of financing comes from a decrease in output. As the average duration increases, $\rho \rightarrow 1$, the importance of real interest rate adjustments dissipates. In the new Keynesian model, real interest rates transmit immediately into movements in the output gap, so at short durations, distortions in output are relatively big. As duration rises, it is optimal to smooth output more, so real interest rate movements diminish. In the 
limit, when $\rho=1$, the present value of real interest rates is zero and it is optimal to make $E_{t} \hat{x}_{t+1}=\hat{x}_{t}$ and rely instead on inflation as a fiscal cushion.

Sources of fiscal financing are particularly sensitive to the level of debt in the economy. Figure 6 reports fiscal financing decompositions under three steady state debt-GDP levels: the calibration to U.S. data (49 percent), "low debt" (20 percent), "high debt" (100 percent). As the level of debt rises, the reliance on tax financing declines. With very short debt duration, changes in real interest rates account for a substantial fraction of financing in high-debt economies. Reliance on real rates declines rapidly as duration rises, with future inflation becoming increasingly important. With long-duration debt, high-debt economies would finance over 20 percent of a fiscal stress innovation with current and future inflation.

Fiscal Financing Decomposition for different debt levels
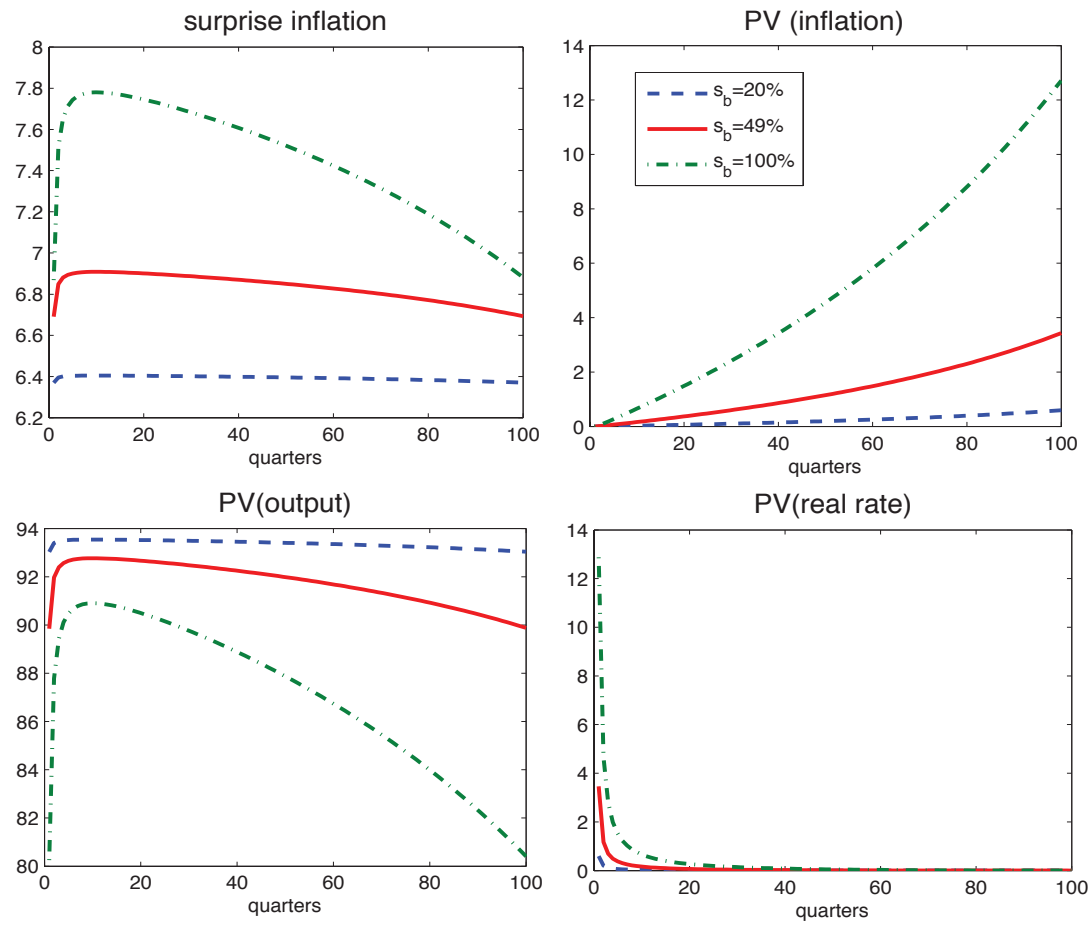

Figure 6: Fraction of fiscal stress innovation financed by each of the four components (81), as a function of average duration of government debt, for three steady state debt-output ratios

\section{Contrast to Conventional Optimal Monetary Policy}

The conventional optimal monetary policy problem, as Woodford (2011) describes, typically assumes a nondistorting source of revenue exists, so that stabilization policy abstracts from fiscal policy distortions. ${ }^{21}$ To place the conventional optimal problem on an equal footing

\footnotetext{
${ }^{21}$ Key earlier expositions of the conventional optimal monetary policy problem include Clarida et al. (1999) and Woodford (2003).
} 
with the fully optimal problem, we have the government optimally choose the interest rate function, taking as given exogenous processes for technology, government spending, the distorting tax rate and wage markup; lump-sum transfers (or taxes) adjust passively to ensure the government's solvency condition never binds. In the conventional problem, the maturity structure of debt is irrelevant. In this section we contrast fully optimal policy to the conventional optimal monetary policy. In both cases, we examine the case of a distorted steady state.

Figure 10 plots the value of the loss function under the conventional optimal monetary policy - straight yellow line - and under the fully optimal monetary and fiscal policies - red line - as a function of the average duration of government debt. These calculations employ the calibration in table 2 for U.S. data. The value of loss objective function under fully optimal polices is hump-shaped in $\rho$, and even though fully optimal policies do not use lump-sum taxes to make the government solvency condition non-binding, welfare is higher under fully optimal policies if the average maturity is long enough (longer than 21 years). The figure shows that welfare under the two optimal policy regimes can be made equivalent by extending the average maturity of bond. However, this welfare-equivalence result and the level of average maturity that achieves the the welfare-equivalence might be sensitive to our calibration.

Figure 10 reports the implications of average debt levels for the threshold value of average maturity that achieves equivalent welfares between fully optimal policies and conventional optimal monetary policy. We consider the range of [20\%, 100\%], which covers most countries' debt-to-GDP ratios in the world. We see that when the debt-to-GDP ratio is at low level (below 40\%), no average maturity exists that achieves equivalent welfares: welfare under fully optimal polices is always inferior to the conventional optimal monetary policy with lump-sum taxes, no matter how long the average maturity. It is possible to achieve welfare equivalence only in medium- to high- debt economies, that is, only when debt-to-GDP ratio is higher than $40 \%$. Moreover, the higher the debt levels, the shorter the threshold value of average maturity to achieve welfare equivalence.

Figure 10 reports the implications of standard deviations of wage markup shock for the threshold value of average maturity that achieves equivalent welfares between fully optimal policies and conventional optimal monetary policy. We consider the range of [0.02, 0.06], which covers most calibrations of standard deviation of wage markup in the literatures.

\section{Concluding Remarks}

This paper examines the joint determination of optimal monetary and fiscal policy in the presence of distorting tax and sticky prices. We study how the presence of long-term bonds affects optimal allocations between inflation and output gap, and the consequent stabilization role for monetary and fiscal policy.

We identified three channels for long-term bonds to have effect on optimal allocations between inflation and output gap. First, long-term bonds affect the aggregate fiscal stress imposed on the intertemporal solvency condition that prevents complete stabilization of inflation and welfare-relevant output gap. Second, long-term bonds facilitate intertemporal smoothing for inflation. Third, which is new in our paper, long-term bond also smoothes welfare-relevant output gap by smoothing real interest rates. 


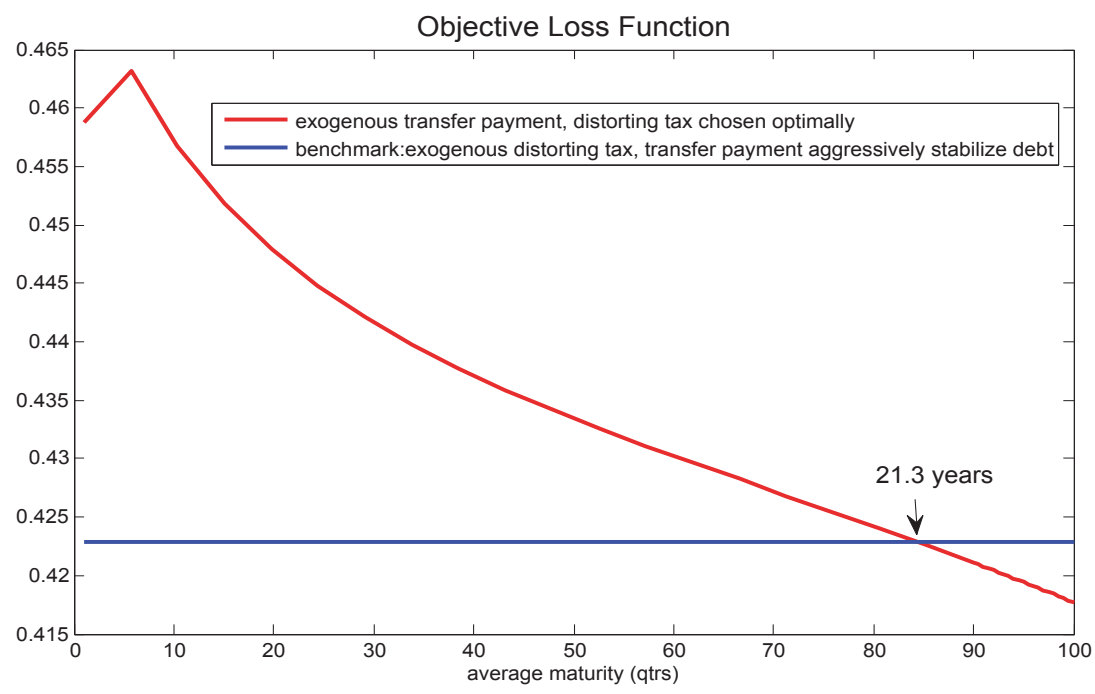

Figure 7: Value of loss function as a percentage of steady state consumption

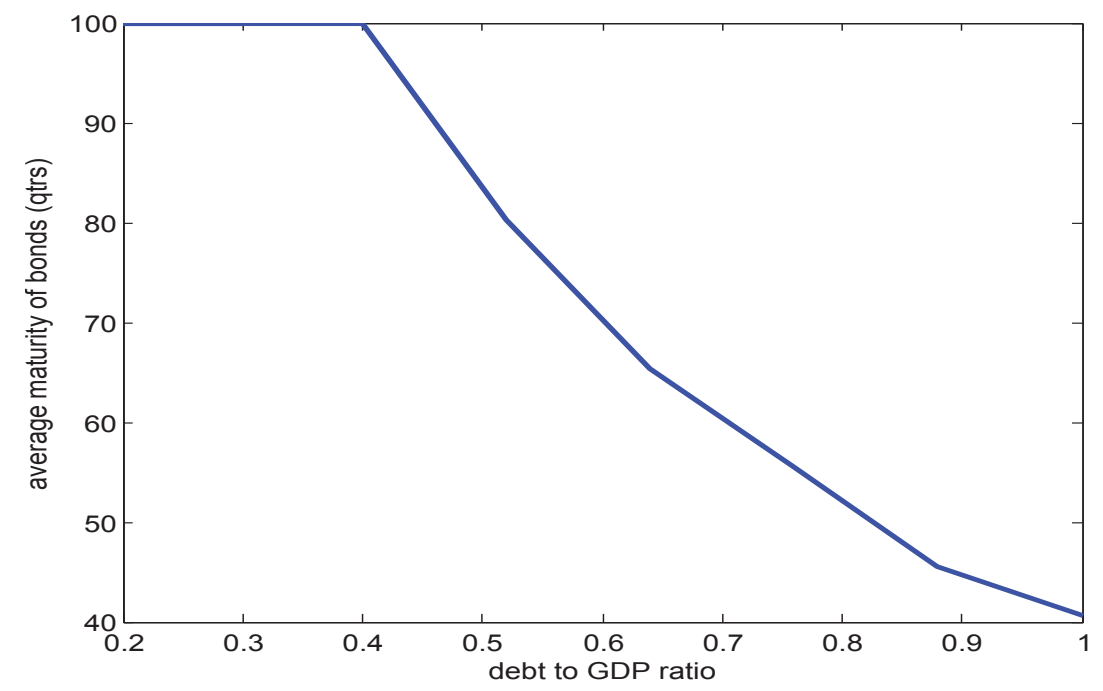

Figure 8: Threshold level of average maturity that equates welfare under fully optimal monetary and fiscal policies and welfare under conventional optimal monetary policy with passively adjusting lump-sum taxes, as a function of debt-output ratio

To study inflation's role as a "fiscal cushion," we use the government's solvency condition to account for the sources of fiscal financing. As the duration of government debt rises, it is optimal to smooth output more and to rely on current and future inflation innovations to revalue government bond. In the limit, with only consol debt, it is optimal to perfectly smooth real interest rates and rely instead on inflation as a fiscal cushion. Sources of fiscal financing are also sensitive to the level of debt in the economy. As the level of bonds rises, the reliance on tax financing declines. With long-duration bond, high-debt economies (100\% debt to GDP ratio) would finance over 20 percent of a fiscal stress innovation with current and future inflation. 


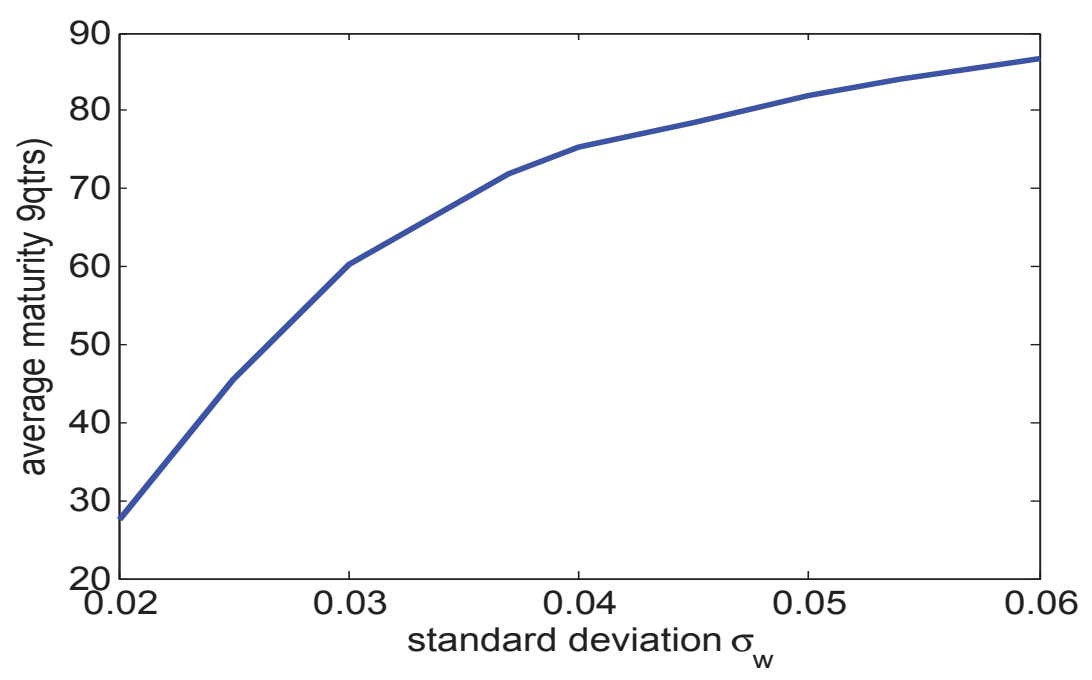

Figure 9: Threshold level of average maturity that equates welfare under fully optimal monetary and fiscal policies and welfare under conventional optimal monetary policy with passively adjusting lump-sum taxes, as a function of the standard deviation of wage markup shock

Finally, we contrast the welfare under fully optimal policy to the conventional optimal monetary policy case where lump-sum taxes are available to always guarantee government solvency. We show that welfare under the two optimal policy regimes can be made equivalent by extending the average maturity of bond. 


\section{REFERENCES}

Aiyagari, S. R., A. Marcet, T. J. Sargent, and J. Seppälä (2002): "Optimal Taxation without State-Contingent Debt," Journal of Political Economy, 110, 1220-1254.

Angeletos, G.-M. (2002): "Fiscal Policy with Non-Contingent Debt and the Optimal Maturity Structure," Quarterly Journal of Economics, 117, 1105-1131.

Barro, R. J. (1979): "On the Determination of the Public Debt," Journal of Political Economy, 87, 940-971.

Benigno, P. And M. Woodford (2004): "Optimal Monetary and Fiscal Policy: A LinearQuadratic Approach," in NBER Macroeconomics Annual 2003, Cambridge, MA: MIT Press, 271-333.

(2007): "Optimal Inflation Targeting under Alternative Fiscal Regimes," in Monetary Policy under Inflation Targeting, Santiago: Central Bank of Chile, 37-75.

Bohn, H. (1990): "Tax Smoothing with Financial Instruments," American Economic Review, 80, 1217-1230.

Buera, F. And J. P. Nicolini (2004): "Optimal Maturity Structure of Government Debt without State Contingent Bonds," Journal of Monetary Economics, 51, 531-554.

Calvo, G. A. (1983): "Staggered Prices in a Utility Maxmimizing Model," Journal of Monetary Economics, 12, 383-398.

Chari, V. V., L. J. Christiano, and P. J. Kehoe (1994): "Optimal Fiscal Policy in a Business Cycle Model," Journal of Political Economy, 102, 617-652.

(1996): "Optimality of the Friedman Rule in Economies with Distorting Taxes," Journal of Monetary Economics, 37, 203-223.

Chari, V. V. and P. J. Kehoe (1999): "Optimal Fiscal and Monetary Policy," in Handbook of Macroeconomics, Volume 1C, ed. by J. B. Taylor and M. Woodford, Amsterdam: Elsevier, 1671-1745.

Clarida, R., J. Galí, and M. Gertler (1999): "The Science of Monetary Policy: A New Keynesian Perspective," Journal of Economic Literature, 37, 1661-1707.

Cochrane, J. H. (2001): "Long Term Debt and Optimal Policy in the Fiscal Theory of the Price Level," Econometrica, 69, 69-116.

Eusepi, S. And B. Preston (2013): "Fiscal Foundations of Inflation: Imperfect Knowledge," Manuscript, Monash University, October.

Galí, J. (1991): "Budget Constraints and Time-Series Evidence on Consumption," American Economic Review, 81, 1238-1253. 
Galí, J., M. Gertler, And J. D. López-Salido (2007): "Markups, Gaps, and the Welfare Costs of Business Fluctuations," Review of Economics and Statistics, 89, 44-59.

Hall, G. J. And T. J. Sargent (2011): "Interest Rate Risk and Other Determinants of Post-WWII U.S. Government Debt/GDP Dynamics," American Economic Journal: Macroeconomics, 3, 1-27.

Hodrick, R. J. And E. C. Prescott (1997): "Postwar U.S. Business Cycles: An Empirical Investigation," Journal of Money, Credit and Banking, 29, 1-16.

Kim, J. AND S. H. Kim (2003): "Spurious Welfare Reversals in International Business Cycle Models," Journal of International Economics, 60, 471-500.

KInG, M. (1995): "Commentary: Monetary Policy Implications of Greater Fiscal Discipline," in Budget Deficits and Debt: Issues and Options, Federal Reserve Bank of Kansas City, 171-183, jackson Hole Symposium.

King, R. G. And C. I. Plosser (1985): "Money, Deficits, and Inflation," CarnegieRochester Conference Series on Public Policy, 22, 147-196.

Kirsanova, T., C. Leith, And S. Wren-Lewis (2009): "Monetary and Fiscal Policy Interaction: The Current Consensus Assignment in the Light of Recent Developments," The Economic Journal, 119, F482-F496.

Kirsanova, T. And S. Wren-Lewis (2012): "Optimal Feedback on Debt in an Economy with Nominal Rigidities," The Economic Journal, 122, 238-264.

Leeper, E. M. (1991): “Equilibria Under 'Active' and 'Passive' Monetary and Fiscal Policies," Journal of Monetary Economics, 27, 129-147.

Lucas, JR., R. E. And N. L. Stokey (1983): "Optimal Fiscal and Monetary Policy in an Economy without Capital," Journal of Monetary Economics, 12, 55-93.

Phelps, E. S. (1973): "Inflation in the Theory of Public Finance," Swedish Journal of Economics, 75, 67-82.

Schmitt-Grohé, S. And M. Uribe (2004): "Optimal Fiscal and Monetary Policy under Sticky Prices," Journal of Economic Theory, 114, 198-230.

- (2007): "Optimal Simple and Implementable Monetary and Fiscal Rules," Journal of Monetary Economics, 54, 1702-1725.

Sims, C. A. (1994): "A Simple Model for Study of the Determination of the Price Level and the Interaction of Monetary and Fiscal Policy," Economic Theory, 4, 381-399.

- (2001): "Fiscal Consequences for Mexico of Adopting the Dollar," Journal of Money, Credit and Banking, 33, 597-616.

(2013): "Paper Money," American Economic Review, 103, 563-84. 
Siu, H. E. (2004): "Optimal Fiscal and Monetary Policy with Sticky Price," Journal of Monetary Economics, 51, 575-607.

TAYlor, J. B. (1979): "Estimation and Control of a Macroeconomic Model with Rational Expectations," Econometrica, 47, 1267-1286.

Woodford, M. (1995): "Price-Level Determinacy Without Control of a Monetary Aggregate," Carnegie-Rochester Conference Series on Public Policy, 43, 1-46.

_ (1998): "Public Debt and the Price Level," Manuscript, Princeton University, July.

- (2001): "Fiscal Requirements for Price Stability," Journal of Money, Credit, and Banking, 33, 669-728.

(2003): Interest and Prices: Foundations of a Theory of Monetary Policy, Princeton, N.J.: Princeton University Press.

(2011): "Optimal Monetary Stabilization Policy," in Handbook of Monetary Economics, ed. by B. M. Friedman and M. Woodford, Amsterdam: Elsevier, vol. 3B, 723-828. 


\section{A Derivation of Long-term Bond Price And IEC}

Define

$$
Q_{t, t+k}=\beta^{k} \frac{U_{c, t+k}}{U_{c, t}} \frac{P_{t}}{P_{t+k}}
$$

as the stochastic discount factor for the price at $\mathrm{t}$ of one unit of composite consumption goods at $t+k$. Then (2) and (3) in the text can be written as

$$
\begin{aligned}
Q_{t}^{S} & =E_{t} Q_{t, t+1} \\
Q_{t}^{M} & =E_{t} Q_{t, t+1}\left(1+\rho Q_{t+1}^{M}\right)
\end{aligned}
$$

Iterating on (A.3) and imposing a terminal condition yields

$$
\begin{aligned}
Q_{t}^{M} & =E_{t}\left[Q_{t, t+1}+\rho Q_{t, t+1} Q_{t+1}^{M}\right] \\
& =E_{t}\left\{Q_{t, t+1}+\rho Q_{t, t+1} E_{t+1} Q_{t+1, t+2}+\rho^{2} Q_{t, t+1} E_{t+1}\left[Q_{t+1, t+2} E_{t+2} Q_{t+2, t+3}\right]+\ldots\right\} \\
& =Q_{t}^{S}+\rho E_{t}\left[Q_{t, t+1} Q_{t+1}^{S}\right]+\rho^{2} E_{t}\left[Q_{t, t+1} E_{t+1}\left(Q_{t+1, t+2} Q_{t+2}^{S}\right)\right]+\ldots \\
& =Q_{t}^{S}+\rho E_{t}\left[Q_{t, t+1} Q_{t+1}^{S}\right]+\rho^{2} E_{t}\left[Q_{t, t+2} Q_{t+2}^{S}\right]+\ldots+\rho^{k} E_{t}\left[Q_{t, t+k} Q_{t+k}^{S}\right]+\ldots \\
& =Q_{t}^{S}+E_{t} \sum_{k=1}^{\infty} \rho^{k} E_{t}\left[Q_{t, t+k} Q_{t+k}^{S}\right]
\end{aligned}
$$

Equation (A.4) implies that the long-term bond's price is determined by weighted average of expectations of future short-term bond's prices.

Substitute (A.1) into (A.4)

$$
\begin{aligned}
Q_{t}^{M} & =E_{t}\left[\beta \frac{U_{c, t+1}}{U_{c, t}} \frac{P_{t}}{P_{t+1}}+\rho \beta^{2} \frac{U_{c, t+2}}{U_{c, t}} \frac{P_{t}}{P_{t+2}}+\ldots+\rho^{k-1} \beta^{k} \frac{U_{c, t+k}}{U_{c, t}} \frac{P_{t}}{P_{t+k}}+\ldots\right] \\
& =E_{t} \sum_{k=1}^{\infty} \rho^{k-1} \beta^{k} \frac{U_{c, t+k}}{U_{c, t}} \frac{P_{t}}{P_{t+k}}
\end{aligned}
$$

Condition (A.5) implies that the long-term bond price is determined by the whole path of expected future price level, discounted by consumption growth rate. The long-term bond price is negatively correlated with expected future inflation rate and consumption growth rate.

Rewrite (A.3) as

$$
\begin{aligned}
Q_{t}^{M} & =E_{t} Q_{t, t+1}\left(1+\rho Q_{t+1}^{M}\right) \\
& =E_{t} Q_{t, t+1} E_{t}\left(1+\rho Q_{t+1}^{M}\right)+\rho \operatorname{cov}\left(Q_{t, t+1}, Q_{t+1}^{M}\right) \\
& =E_{t} Q_{t}^{S}\left(1+\rho Q_{t+1}^{M}\right)+\rho \operatorname{cov}\left(Q_{t, t+1}, Q_{t+1}^{M}\right)
\end{aligned}
$$

Recall from (A.5) that

$$
Q_{t+1}^{M}=E_{t} \sum_{k=1}^{\infty} \rho^{k-1} Q_{t+1, t+1+k}
$$

$Q_{t+1}^{M}$ is determined by weighted average of expected future discounted value of future stochastic discount factors. Therefore, without loss of generality, we assume $\operatorname{cov}\left(Q_{t, t+1}, Q_{t+1}^{M}\right)=0$, and (A.6) can be expressed as

$$
Q_{t}^{M}=E_{t} Q_{t}^{S}\left(1+\rho Q_{t+1}^{M}\right)
$$


To derive intertemporal equilibrium condition, we iterate on government's period budget constraint, (9), and impose asset-pricing relations and the household's transversality condition:

$$
\begin{aligned}
\left(1+\rho Q_{t}^{M}\right) \frac{B_{t-1}^{M}}{P_{t}} & =Q_{t}^{M} \frac{B_{t}^{M}}{P_{t}}+S_{t} \\
& =E_{t}\left[\frac{Q_{t}^{M} Q_{t+1}^{M} \pi_{t+1}}{1+\rho Q_{t+1}^{M}} \frac{B_{t}^{M}}{P_{t}}+\frac{Q_{t}^{M} \pi_{t+1}}{1+\rho Q_{t+1}^{M}} S_{t+1}+S_{t}\right] \\
& =E_{t}\left[S_{t}+\frac{Q_{t}^{M} \pi_{t+1}}{1+\rho Q_{t+1}^{M}} S_{t+1}+\frac{Q_{t}^{M} Q_{t+1}^{M} \pi_{t+1} \pi_{t+2}}{\left(1+\rho Q_{t+1}^{M}\right)\left(1+\rho Q_{t+2}^{M}\right)} S_{t+2}+\ldots\right]
\end{aligned}
$$

Substituting (A.1) and (A.3) into (A.8) yields

$$
\left(1+\rho Q_{t}^{M}\right) \frac{B_{t-1}^{M}}{P_{t}}=E_{t} \sum_{i=0}^{\infty} \beta^{i} \frac{U_{c, t+i}}{U_{c, t}} S_{t+i}
$$

To derive (11) in the text, combine (A.5) and (A.9)

$$
E_{t}\left(\sum_{k=0}^{\infty} \rho^{k} \beta^{k} \frac{U_{c, t+k}}{U_{c, t}} \frac{1}{P_{t+k}}\right) B_{t-1}^{M}=E_{t} \sum_{i=0}^{\infty} \beta^{i} \frac{U_{c, t+i}}{U_{c, t}} S_{t+i}
$$

\section{B Derivation of Nonlinear First Order Conditions}

The full nonlinear optimal policy problem maximizes

$$
E_{0} \sum_{t=0}^{\infty} \beta^{t} U\left(Y_{t}, \Delta_{t}, \xi_{t}\right)
$$

subject to

$$
\begin{aligned}
& {\left[\frac{1-\theta \pi_{t}^{\epsilon-1}}{1-\theta}\right]^{\frac{1+\epsilon \varphi}{1-\epsilon}}=\frac{\epsilon}{\epsilon-1} \frac{K_{t}}{J_{t}}} \\
& K_{t}=\left(\frac{Y_{t}}{A_{t}}\right)^{\varphi+1}+\beta \theta E_{t} K_{t+1} \pi_{t+1}^{\epsilon(1+\varphi)} \\
& J_{t}=\left(1-\tau_{t}\right) U_{c, t} Y_{t}+\beta \theta E_{t} J_{t+1} \pi_{t+1}^{\epsilon-1} \\
& \left(1+\rho Q_{t}^{M}\right) \frac{b_{t-1}^{M}}{\pi_{t}}=Q_{t}^{M} b_{t}^{M}+\tau_{t} Y_{t}-Z_{t}-G_{t} \\
& Q_{t}^{M}=\beta E_{t} \frac{U_{c, t+1}}{U_{c, t}} \frac{1}{\pi_{t+1}}\left(1+\rho Q_{t+1}^{M}\right) \\
& \Delta_{t}=(1-\theta)\left[\frac{1-\theta \pi_{t}^{\epsilon-1}}{1-\theta}\right]^{\frac{\epsilon(1+\varphi)}{\epsilon-1}}+\theta \pi_{t}^{\epsilon(1+\varphi)} \Delta_{t-1}
\end{aligned}
$$


The first-order conditions are

$$
\begin{aligned}
Y_{t}: & U_{Y, t}-\lambda_{t}^{2}(\varphi+1) A_{t}^{-(\varphi+1)} Y_{t}^{\varphi}-\lambda_{t}^{3}\left(1-\tau_{t}\right)\left(U_{c, t}+U_{c c, t} Y_{t}\right)-\lambda_{t}^{4} \tau_{t} \\
& -\beta \sigma \lambda_{t}^{5} \frac{1+\rho Q_{t+1}}{\pi_{t+1}} C_{t+1}^{-\sigma} C_{t}^{\sigma-1}+\sigma \lambda_{t-1}^{5} \frac{1+\rho Q_{t}}{\pi_{t}} C_{t-1}^{\sigma} C_{t}^{-\sigma-1}=0 \\
\pi_{t}: & \lambda_{t}^{1} \frac{1+\epsilon \varphi}{1-\epsilon} p\left(\pi_{t}\right)^{\frac{1+\epsilon \varphi}{1-\epsilon}-1} p^{\prime}\left(\pi_{t}\right)-\lambda_{t-1}^{2} \theta \epsilon(1+\varphi) K_{t} \pi_{t}^{\epsilon(1+\varphi)-1}-\lambda_{t-1}^{3} \theta(\epsilon-1) J_{t} \pi_{t}^{\epsilon-2} \\
& -\lambda_{t}^{4}\left(1+\rho Q_{t}^{M}\right) b_{t-1} \pi_{t}^{-2}+\lambda_{t-1}^{5} \frac{U_{c, t}}{U_{c, t-1}}\left(1+\rho Q_{t}^{M}\right) \pi_{t}^{-2} \\
& -\lambda_{t}^{6}\left[(1-\theta) \frac{\epsilon(1+\varphi)}{\epsilon-1} p\left(\pi_{t}\right)^{\frac{1+\epsilon \varphi}{\epsilon-1}} p^{\prime}\left(\pi_{t}\right)+\theta \epsilon(1+\varphi) \Delta_{t-1} \pi_{t}^{\epsilon(1+\varphi)-1}\right]=0 \\
\Delta_{t}: & U_{\Delta, t}+\lambda_{t}^{6}-E_{t} \lambda_{t+1}^{6} \beta \theta \pi_{t+1}^{\epsilon(1+\varphi)}=0 \\
K_{t}: & -\lambda_{t}^{1} \frac{\epsilon}{\epsilon-1} \frac{1}{J_{t}}+\lambda_{t}^{2}-\lambda_{t-1}^{2} \theta \pi_{t}^{\epsilon(1+\varphi)}=0 \\
J_{t}: & \lambda_{t}^{1} \frac{\epsilon}{\epsilon-1} \frac{K_{t}}{J_{t}^{2}}+\lambda_{t}^{3}-\lambda_{t-1}^{3} \theta \pi_{t}^{\epsilon-1}=0 \\
\tau_{t}: & \lambda_{t}^{3} U_{c, t}-\lambda_{t}^{4}=0 \\
b_{t}: & \lambda_{t}^{4}-E_{t} \lambda_{t+1}^{4} \frac{U_{c, t}}{U_{c, t+1}}=0 \\
Q_{t}^{M}: & \lambda_{t}^{4}\left(\rho \frac{b_{t-1}}{\pi_{t}}-b_{t}\right)+\lambda_{t}^{5}-\lambda_{t-1}^{5} \frac{\rho}{\pi_{t}} \frac{U_{c, t}}{U_{c, t-1}}=0
\end{aligned}
$$

If we redefine $\tilde{\lambda}_{t}^{1}=\frac{\lambda_{t}^{1}}{J_{t}}, \tilde{\lambda}_{t}^{2}=\lambda_{t}^{2}, \tilde{\lambda}_{t}^{3}=\lambda_{t}^{3}, \tilde{\lambda}_{t}^{4}=\frac{\lambda_{t}^{4}}{U_{c, t}}, \tilde{\lambda}_{t}^{5}=\frac{\lambda_{t}^{5}}{U_{c, t} b_{t}}, \tilde{\lambda}_{t}^{6}=\lambda_{t}^{6}$, then the first-order conditions can be simplified as

$$
\begin{aligned}
Y_{t}: & U_{Y, t}-\tilde{\lambda}_{t}^{2}(\varphi+1) A_{t}^{-(\varphi+1)} Y_{t}^{\varphi}-\tilde{\lambda}_{t}^{3}\left(1-\tau_{t}\right)\left(U_{c, t}+U_{c c, t} Y_{t}\right)-\tilde{\lambda}_{t}^{4} \tau_{t} U_{c, t} \\
& -\beta \sigma \tilde{\lambda}_{t}^{5} \frac{\left(1+\rho Q_{t+1}\right) b_{t}}{\pi_{t+1}} C_{t+1}^{-\sigma} C_{t}^{-1}+\sigma \tilde{\lambda}_{t-1}^{5} \frac{\left(1+\rho Q_{t}\right) b_{t-1}}{\pi_{t}} C_{t}^{-\sigma-1}=0 \\
\pi_{t}: & \tilde{\lambda}_{t}^{1} J_{t} \frac{1+\epsilon \varphi}{1-\epsilon} p\left(\pi_{t}\right)^{\frac{1+\epsilon \varphi}{1-\epsilon}-1} p^{\prime}\left(\pi_{t}\right)-\tilde{\lambda}_{t-1}^{2} \theta \epsilon(1+\varphi) K_{t} \pi_{t}^{\epsilon(1+\varphi)-1}-\tilde{\lambda}_{t-1}^{3} \theta(\epsilon-1) J_{t} \pi_{t}^{\epsilon-2} \\
& -\tilde{\lambda}_{t}^{4} U_{c, t}\left(1+\rho Q_{t}^{M}\right) b_{t-1} \pi_{t}^{-2}+\tilde{\lambda}_{t-1}^{5} U_{c, t}\left(1+\rho Q_{t}^{M}\right) b_{t-1} \pi_{t}^{-2} \\
& -\tilde{\lambda}_{t}^{6}\left[(1-\theta) \frac{\epsilon(1+\varphi)}{\epsilon-1} p\left(\pi_{t}\right)^{\frac{1+\epsilon \varphi}{\epsilon-1}} p^{\prime}\left(\pi_{t}\right)+\theta \epsilon(1+\varphi) \Delta_{t-1} \pi_{t}^{\epsilon(1+\varphi)-1}\right]=0 \\
\Delta_{t}: & U_{\Delta, t}+\tilde{\lambda}_{t}^{6}-E_{t} \tilde{\lambda}_{t+1}^{6} \beta \theta \pi_{t+1}^{\epsilon(1+\varphi)}=0 \\
K_{t}: & -\frac{\epsilon}{\epsilon-1} \tilde{\lambda}_{t}^{1}+\tilde{\lambda}_{t}^{2}-\tilde{\lambda}_{t-1}^{2} \theta \pi_{t}^{\epsilon(1+\varphi)}=0 \\
J_{t}: & \tilde{\lambda}_{t}^{1}+\tilde{\lambda}_{t}^{3}-\tilde{\lambda}_{t-1}^{3} \theta \pi_{t}^{\epsilon-1}=0 \\
\tau_{t}: & \tilde{\lambda}_{t}^{3}-\tilde{\lambda}_{t}^{4}=0 \\
b_{t}: & \tilde{\lambda}_{t}^{4}-E_{t} \tilde{\lambda}_{t+1}^{4}=0 \\
Q_{t}^{M}: & \tilde{\lambda}_{t}^{4}\left(\rho \frac{b_{t-1}}{\pi_{t}}-b_{t}\right)+\tilde{\lambda}_{t}^{5} b_{t}-\tilde{\lambda}_{t-1}^{5} \rho \frac{b_{t-1}}{\pi_{t}}=0
\end{aligned}
$$

where $\tilde{\lambda}_{t}^{1}$ through $\tilde{\lambda}_{t}^{6}$ are the Lagrange multipliers. Condition (B.13) implies that the evolution of the Lagrange multiplier corresponding to the government budget $\tilde{\lambda}_{t}^{4}$ obeys a martingale. Condition (B.14) connects $\tilde{\lambda}_{t}^{4}$ to the Lagrange multiplier corresponding to the maturity structure $\tilde{\lambda}_{t}^{5}$. 
Conditions (B.10) - (B.12) relate $\tilde{\lambda}_{t}^{4}$ to the Lagrange multiplier corresponding to the aggregate supply relations $\tilde{\lambda}_{t}^{1}, \tilde{\lambda}_{t}^{2}, \tilde{\lambda}_{t}^{3}$. Conditions (B.7) and (B.9) implicitly determine the shadow price of the each constraint. Notice that (B.9) determines the marginal utility loss from inflation, while (B.7) determines the marginal utility loss from variations in output-gap.

B.1 Deterministic Steady State Using the optimal allocation that appendix B describes, in a steady state with zero net inflation, $\bar{\pi}=1$, we have

$$
\bar{\Delta}=1, \quad \frac{\bar{K}}{\bar{J}}=\frac{\epsilon-1}{\epsilon}, \quad \bar{Q}^{s}=\beta \quad \frac{\bar{b}}{\bar{S}}=\frac{1-\beta \rho}{1-\beta}
$$

The associated steady-state price of long-term bond is given by

$$
\bar{Q}^{M}=\frac{\beta}{1-\beta \rho}
$$

which is increasing in average maturity $\rho$. The intuition is very straightforward, long-term debt yields more coupon payments and therefore demands higher price.

The steady-state government budget constraint implies

$$
\bar{\tau}-s_{g}-s_{z}=\left(\beta^{-1}-1\right) s_{b}
$$

where $s_{b} \equiv \bar{Q}^{M} \bar{B} / \bar{Y}$ is the steady-state debt to GDP ratio, $s_{g} \equiv \bar{G} / \bar{Y}$ is the steady state government purchases to GDP ratio, $s_{z} \equiv \bar{Z} / \bar{Y}$ is the steady-state government transfers to GDP ratio.

Steady-state Lagrangian multipliers satisfy

$$
\begin{aligned}
& \overline{\tilde{\lambda}}^{1}=(\theta-1) \overline{\tilde{\lambda}}^{3} \\
& \overline{\tilde{\lambda}}^{2}=\frac{\epsilon}{1-\epsilon} \overline{\tilde{\lambda}}^{3} \\
& \overline{\tilde{\lambda}}^{3}=\overline{\tilde{\lambda}}^{4} \\
& \overline{\tilde{\lambda}}^{5}=\overline{\tilde{\lambda}}^{4} \\
& (1-\beta \theta) \overline{\tilde{\lambda}}^{6}=-U_{\Delta}(\bar{Y}, 1) \\
& {\left[\frac{\epsilon(\varphi+1)}{1-\epsilon} \bar{Y}^{\varphi}+\bar{U}_{c}+(1-\bar{\tau}) \bar{U}_{c c} \bar{Y}-\frac{(1-\beta) \sigma}{1-\beta \rho} \frac{s_{b}}{s_{c}} \bar{U}_{c}\right] \overline{\tilde{\lambda}}^{4}=U_{Y}(\bar{Y}, 1)}
\end{aligned}
$$

Note that $\overline{\tilde{\lambda}}^{4}$ and $\overline{\tilde{\lambda}}^{6}$ can be solved from (B.19) and (B.20), and at steady state the other multipliers are proportional to $\overline{\tilde{\lambda}}^{4}$. At steady state, the Lagrange multiplier associated with government budget therefore completely summarizes the distortions from output; the price dispersion summarizes the distortions from inflation.

\section{Second-Order Approximation to Utility}

The life-time welfare of household is defined by

$$
U_{0}=E_{0} \sum_{t=0}^{\infty} \beta^{t} U\left(Y_{t}, \Delta_{t}, \xi_{t}\right)
$$

where

$$
\begin{aligned}
U\left(Y_{t}, \Delta_{t}, \xi_{t}\right) & =\frac{\left(Y_{t}-G_{t}\right)^{1-\sigma}}{1-\sigma}-\frac{\left(\frac{Y_{t}}{A_{t}}\right)^{1+\varphi}}{1+\varphi} \Delta_{t} \\
& =u\left(Y_{t}, G_{t}\right)-v\left(Y_{t}, \Delta_{t}, A_{t}\right)
\end{aligned}
$$


We use a second-order Taylor expansion for a variable $X_{t}$ :

$$
X_{t} / \bar{X}=e^{\ln X_{t} / \bar{X}}=e^{\hat{X}_{t}}=1+\hat{X}_{t}+\frac{1}{2} \hat{X}_{t}^{2}
$$

and

$$
\tilde{X}_{t}=X_{t}-\bar{X}=\bar{X}\left(\hat{X}_{t}+\frac{1}{2} \hat{X}_{t}^{2}\right)
$$

The derivation of second-order approximation closely follows Benigno and Woodford (2004).

The first term in (C.2) can be approximated to second order as

$$
\begin{aligned}
u\left(Y_{t}, G_{t}\right)-\bar{u} & =\bar{u}_{Y} \tilde{Y}_{t}+\bar{u}_{G} \tilde{G}_{t}+\bar{u}_{Y G} \tilde{Y}_{t} \tilde{G}_{t}+\frac{1}{2} \bar{u}_{Y Y} \tilde{Y}_{t}^{2}+\frac{1}{2} \bar{u}_{G G} \tilde{G}_{t}^{2}+\mathcal{O}\left(\left\|\xi_{t}\right\|^{3}\right) \\
& =\bar{u}_{Y} \bar{Y}\left(\hat{Y}_{t}+\frac{1}{2} \hat{Y}_{t}^{2}\right)+\bar{u}_{G} \tilde{G}_{t}+\bar{u}_{Y G} \bar{Y} \bar{G}_{t} \hat{G}_{t}+\frac{1}{2} \bar{u}_{Y Y} \bar{Y}^{2} \hat{Y}_{t}^{2}+\frac{1}{2} \bar{u}_{G G} \tilde{G}_{t}^{2}+\mathcal{O}\left(\left\|\xi_{t}\right\|^{3}\right) \\
& =\bar{u}_{Y} \bar{Y}\left(\hat{Y}_{t}+\frac{1}{2} \hat{Y}_{t}^{2}\right)+\bar{u}_{Y G} \bar{Y} \bar{G}_{t} \hat{G}_{t}+\frac{1}{2} \bar{u}_{Y Y} \bar{Y}^{2} \hat{Y}_{t}^{2}+\mathcal{O}\left(\left\|\xi_{t}\right\|^{3}\right)+t . i . p . \\
& =\bar{u}_{Y} \bar{Y}\left[\hat{Y}_{t}+\frac{1}{2}\left(1+\frac{\bar{u}_{Y Y}}{\bar{u}_{Y}} \bar{Y}\right) \hat{Y}_{t}^{2}-\frac{\bar{u}_{Y Y}}{\bar{u}_{Y}} \bar{G}_{G_{t}} \hat{Y}_{t}\right]+\mathcal{O}\left(\left\|\xi_{t}\right\|^{3}\right)+\text { t.i.p. } \\
& =\bar{u}_{Y} \bar{Y}\left[\hat{Y}_{t}+\frac{1}{2}\left(1-s_{c}^{-1} \sigma\right) \hat{Y}_{t}^{2}+s_{g} s_{c}{ }^{-1} \sigma \hat{G}_{t} \hat{Y}_{t}\right]+\mathcal{O}\left(\left\|\xi_{t}\right\|^{3}\right)+\text { t.i.p. }
\end{aligned}
$$

"t.i.p." represents the terms that are independent of policy. The second term in (C.2) can be approximated by

$$
\begin{aligned}
& v\left(Y_{t}, \Delta_{t}, A_{t}\right)-\bar{v}=\bar{v}_{Y} \tilde{Y}_{t}+\bar{v}_{A} \tilde{A}_{t}+\bar{v}_{\Delta} \tilde{\Delta}_{t}+\bar{v}_{Y A} \tilde{Y}_{t} \tilde{A}_{t}+\bar{v}_{Y \Delta} \tilde{Y}_{t} \tilde{\Delta}_{t}+\bar{v}_{\Delta A} \tilde{\Delta}_{t} \tilde{A}_{t} \\
& +\frac{1}{2} \bar{v}_{Y Y} \tilde{Y}_{t}^{2}+\frac{1}{2} \bar{v}_{A A} \tilde{A}_{t}^{2}+\frac{1}{2} \bar{v}_{\Delta \Delta} \tilde{\Delta}_{t}^{2}+\mathcal{O}\left(\left\|\xi_{t}\right\|^{3}\right) \\
& =\bar{v}_{Y} \tilde{Y}_{t}+\bar{v}_{\Delta} \tilde{\Delta}_{t}+\bar{v}_{Y A} \tilde{Y}_{t} \tilde{A}_{t}+\bar{v}_{Y \Delta} \tilde{Y}_{t} \tilde{\Delta}_{t}+\bar{v}_{\Delta A} \tilde{\Delta}_{t} \tilde{A}_{t} \\
& +\frac{1}{2} \bar{v}_{Y Y} \tilde{Y}_{t}^{2}+\frac{1}{2} \bar{v}_{\Delta \Delta} \tilde{\Delta}_{t}^{2}+\mathcal{O}\left(\left\|\xi_{t}\right\|^{3}\right)+\text { t.i.p. } \\
& =\bar{v}_{Y} \bar{Y}\left(\hat{Y}_{t}+\frac{1}{2} \hat{Y}_{t}^{2}\right)+\bar{v}_{\Delta} \tilde{\Delta}_{t}+\bar{v}_{Y A} \bar{Y} \hat{Y}_{t} \tilde{A}_{t}+\bar{v}_{Y \Delta} \bar{Y} \hat{Y}_{t} \tilde{\Delta}_{t}+\bar{v}_{\Delta A} \tilde{\Delta}_{t} \tilde{A}_{t} \\
& +\frac{1}{2} \bar{v}_{Y Y} \bar{Y}^{2} \hat{Y}_{t}^{2}+\frac{1}{2} \bar{v}_{\Delta \Delta} \tilde{\Delta}_{t}^{2}+\mathcal{O}\left(\left\|\xi_{t}\right\|^{3}\right)+\text { t.i.p. } \\
& =\bar{v}_{Y} \bar{Y}\left[\hat{Y}_{t}+\frac{1}{2}\left(1+\frac{\bar{v}_{Y Y} \bar{Y}}{\bar{v}_{Y}}\right) \hat{Y}_{t}^{2}+\frac{\bar{v}_{\Delta}}{\bar{v}_{Y} \bar{Y}} \tilde{\Delta}_{t}+\frac{\bar{v}_{Y \Delta}}{\bar{v}_{Y}} \tilde{\Delta}_{t} \hat{Y}_{t}+\frac{\bar{v}_{Y A}}{\bar{v}_{Y}} \tilde{A}_{t} \hat{Y}_{t}+\frac{\bar{v}_{\Delta A}}{\bar{v}_{Y} \bar{Y}_{t}} \tilde{\Delta}_{t} \tilde{A}_{t}+\frac{1}{2} \bar{v}_{\Delta \Delta} \tilde{v}_{Y} \bar{Y} \tilde{\Delta}_{t}^{2}\right] \\
& +\mathcal{O}\left(\left\|\xi_{t}\right\|^{3}\right)+\text { t.i.p. } \\
& =\bar{v}_{Y} \bar{Y}\left[\hat{Y}_{t}+\frac{1}{2}(1+\varphi) \hat{Y}_{t}^{2}+\frac{1}{1+\varphi} \tilde{\Delta}_{t}+\tilde{\Delta}_{t} \hat{Y}_{t}-(1+\varphi) \hat{Y}_{t} \tilde{A}_{t}-\tilde{\Delta}_{t} \tilde{A}_{t}\right]+\mathcal{O}\left(\left\|\xi_{t}\right\|^{3}\right)+\text { t.i.p. }
\end{aligned}
$$

From Benigno and Woodford (2004) we know that a second order approximation to (B.6) yields

$$
\tilde{\Delta}_{t}=\theta \tilde{\Delta}_{t-1}+\frac{\theta \epsilon}{1-\theta}(1+\varphi)(1+\epsilon \varphi) \frac{\hat{\pi}_{t}^{2}}{2}+\mathcal{O}\left(\left\|\xi_{t}\right\|^{3}\right)+t . i . p .
$$

which implies that $\tilde{\Delta}_{t}=\mathcal{O}\left(\pi_{t}^{2}\right)$. 
Therefore (C.6) can be simplified as

$v\left(Y_{t}, \Delta_{t}, A_{t}\right)-\bar{v}=\bar{v}_{Y} \bar{Y}\left[\hat{Y}_{t}+\frac{1}{2}(1+\varphi) \hat{Y}_{t}^{2}+\frac{1}{1+\varphi} \tilde{\Delta}_{t}-(1+\varphi) \hat{Y}_{t} \hat{A}_{t}\right]+\mathcal{O}\left(\left\|\xi_{t}\right\|^{3}\right)+$ t.i.p.

Combine (C.5) and (C.8) and apply the relation $\bar{v}_{Y}=(1-\Phi) \bar{u}_{Y}$, we approximate the life-time utility (C.1) as

$$
\begin{aligned}
U_{0}-\bar{U}_{0}= & \bar{u}_{Y} \bar{Y} E_{0} \sum_{t=0}^{\infty} \beta^{t}\left\{\Phi \hat{Y}_{t}+\frac{1}{2}\left[\left(1-\frac{\sigma}{s_{c}}\right)-(1-\Phi)(1+\varphi)\right] \hat{Y}_{t}^{2}+\left[s_{g} s_{c}{ }^{-1} \sigma \hat{G}_{t}+(1-\Phi)(1+\varphi) \hat{A}_{t}\right] \hat{Y}_{t}-\frac{1-\Phi}{1+\varphi} \hat{\Delta}_{t}\right\} \\
& +\mathcal{O}\left(\left\|\xi_{t}\right\|^{3}\right)+\text { t.i.p. }
\end{aligned}
$$

From Benigno and Woodford (2004) we observe

$$
E_{0} \sum_{t=0}^{\infty} \beta^{t} \hat{\Delta}_{t}=\frac{\theta \epsilon}{(1-\theta)(1-\beta \theta)}(1+\varphi)(1+\epsilon \varphi) \sum_{t=0}^{\infty} \beta^{t} \frac{\hat{\pi}_{t}^{2}}{2}
$$

Therefore, the second-order approximation to the life-time utility (C.1) can be further expressed as

$$
U_{0}-\bar{U}_{0}=\bar{u}_{Y} \bar{Y} E_{0} \sum_{t=0}^{\infty} \beta^{t}\left\{A_{y} \hat{Y}_{t}+\frac{1}{2} A_{y y} \hat{Y}_{t}^{2}+A_{\xi}^{\prime} \hat{\xi}_{t} \hat{Y}_{t}-\frac{A_{\pi}}{2} \hat{\pi}_{t}^{2}\right\}+\mathcal{O}\left(\left\|\xi_{t}\right\|^{3}\right)+\text { t.i.p. }
$$

where

$$
\begin{aligned}
A_{y} & =\Phi \\
A_{y y} & =\left(1-\sigma s_{c}{ }^{-1}\right)-(1-\Phi)(1+\varphi) \\
A_{\xi}^{\prime} \hat{\xi}_{t} & =\sigma s_{c}{ }^{-1} s_{g} \hat{G}_{t}+(1-\Phi)(1+\varphi) \hat{A}_{t} \\
A_{\pi} & =(1-\Phi) \frac{\theta \epsilon(1+\epsilon \varphi)}{(1-\theta)(1-\beta \theta)}
\end{aligned}
$$

$\Phi=1-(1-\tau) \frac{\epsilon-1}{\epsilon}$ measures the inefficiency of steady state of output. $s_{c}=\frac{\bar{C}}{\bar{Y}}$ is steady state consumption to GDP ratio; $s_{g}=\frac{\bar{G}}{Y}$ is steady state government spending to GDP ratio.

\section{Second-Order Approximation to Government's IEC}

Recall the government budget constraint

$$
Q_{t}^{M} b_{t}^{M}+S_{t}=\left(1+\rho Q_{t}^{M}\right) \frac{b_{t-1}^{M}}{\pi_{t}}
$$

and no-arbitrage condition

$$
Q_{t}^{M}=\beta E_{t} \frac{U_{c, t+1}}{U_{c, t}} \frac{1}{\pi_{t+1}}\left(1+\rho Q_{t+1}^{M}\right)
$$

Define

$$
W_{t}=U_{c, t}\left(1+\rho Q_{t}^{M}\right) \frac{b_{t-1}^{M}}{\pi_{t}}
$$


By applying (D.2) and (D.3), (D.1) can be rewritten as

$$
W_{t}=U_{c, t} S_{t}+\beta E_{t} W_{t+1}
$$

and

$$
W_{t}=E_{t} \sum_{k=0}^{\infty} U_{c, t+k} S_{t+k}
$$

A second-order approximation to $U_{c, t} S_{t}$ yields

$$
U_{c, t} S_{t}=\bar{U}_{c} \bar{S}+\bar{U}_{c c} \bar{S} \tilde{C}_{t}+\bar{U}_{c} \tilde{S}_{t}+\frac{1}{2} \bar{S} \bar{U}_{c c c} \tilde{C}_{t}^{2}+\bar{U}_{c c} \tilde{S}_{t} \tilde{C}_{t}
$$

We express $\tilde{C}_{t}$ in terms of $\hat{Y}_{t}$ and $\hat{G}_{t}$ through the second order approximation to the identity $C_{t}=Y_{t}-G_{t}$

$$
\tilde{C}_{t}=\bar{Y}\left(\hat{Y}_{t}+\frac{1}{2} \hat{Y}_{t}^{2}\right)-\bar{G}\left(\hat{G}_{t}+\frac{1}{2} \hat{G}_{t}^{2}\right)
$$

Since $S_{t}=\tau_{t} Y_{t}-G_{t}-Z_{t}$, a second-order approximation to the primary surplus can be written as

$$
\tilde{S}_{t}=\bar{\tau} \bar{Y}\left(\hat{\tau}_{t}+\hat{Y}_{t}\right)+\frac{1}{2} \bar{\tau} \bar{Y}\left(\hat{\tau}_{t}^{2}+\hat{Y}_{t}^{2}\right)+\bar{\tau} \bar{Y} \hat{Y}_{t} \hat{\tau}_{t}-\bar{G}\left(\hat{G}_{t}+\frac{1}{2} \hat{G}_{t}^{2}\right)-\bar{Z}\left(\hat{Z}_{t}+\frac{1}{2} \hat{Z}_{t}^{2}\right)
$$

Substituting (D.7) and (D.8) into (D.6), we obtain

$$
\begin{aligned}
U_{c, t} S_{t}-\bar{U}_{c} \bar{S}= & \bar{U}_{c c} \bar{S}\left[\bar{Y}\left(\hat{Y}_{t}+\frac{1}{2} \hat{Y}_{t}^{2}\right)-\bar{G}\left(\hat{G}_{t}+\frac{1}{2} \hat{G}_{t}^{2}\right)\right] \\
& +\bar{U}_{c}\left[\bar{\tau} \bar{Y}\left(\hat{\tau}_{t}+\hat{Y}_{t}\right)+\frac{1}{2} \bar{\tau} \bar{Y}\left(\hat{\tau}_{t}^{2}+\hat{Y}_{t}^{2}\right)+\bar{\tau} \bar{Y} \hat{Y}_{t} \hat{\tau}_{t}-\bar{G}\left(\hat{G}_{t}+\frac{1}{2} \hat{G}_{t}^{2}\right)-\bar{Z}\left(\hat{Z}_{t}+\frac{1}{2} \hat{Z}_{t}^{2}\right)\right] \\
& +\frac{1}{2} \bar{S} \bar{U}_{c c c}\left(\bar{Y}^{2} \hat{Y}_{t}^{2}+\bar{G}^{2} \hat{G}_{t}^{2}-2 \bar{Y} \bar{G} \hat{Y}_{t} \hat{G}_{t}\right) \\
& +\bar{U}_{c c}\left[\bar{\tau} \bar{Y}^{2} \hat{Y}_{t}^{2}+\bar{\tau} \bar{Y}^{2} \hat{Y}_{t} \hat{\tau}_{t}-(\bar{\tau}+1) \bar{Y} \bar{G} \hat{Y}_{t} \hat{G}_{t}-\bar{Y} \bar{Z} \hat{Y}_{t} \hat{Z}_{t}-\bar{\tau} \bar{Y} \bar{G} \hat{\tau}_{t} \hat{G}_{t}+\bar{G}^{2} \hat{G}_{t}^{2}+\bar{G} \bar{Z} \hat{G}_{t} \hat{Z}_{t}\right] \\
& +\mathcal{O}\left(\left\|\xi_{t}\right\|^{3}\right) \\
=\bar{U}_{c} \bar{S}[ & -\sigma s_{c}^{-1}\left(\hat{Y}_{t}+\frac{1}{2} \hat{Y}_{t}^{2}\right)+\sigma s_{c}^{-1} s_{g}\left(\hat{G}_{t}+\frac{1}{2} \hat{G}_{t}^{2}\right)+\frac{\bar{\tau} \bar{Y}}{\bar{S}}\left(\hat{\tau}_{t}+\hat{Y}_{t}\right)+\frac{1}{2} \frac{\bar{\tau} \bar{Y}}{\bar{S}}\left(\hat{\tau}_{t}^{2}+\hat{Y}_{t}^{2}\right)+\frac{\bar{\tau} \bar{Y}}{\bar{S}} \hat{Y}_{t} \hat{\tau}_{t}-\frac{\bar{G}}{\bar{S}} \hat{G}_{t}-\frac{\bar{Z}}{\bar{S}} \hat{Z}_{t} \\
& +\frac{1}{2} \sigma(1+\sigma)\left(s_{c}^{-2} \hat{Y}_{t}^{2}+s_{g}^{2} s_{c}^{-2} \hat{G}_{t}^{2}-2 s_{g} s_{c}^{-2} \hat{Y}_{t} \hat{G}_{t}\right) \\
& \left.-\sigma s_{c}^{-1} \frac{\bar{\tau} \bar{Y}}{\bar{S}}\left(\hat{Y}_{t}^{2}+\hat{Y}_{t} \hat{\tau}_{t}\right)+\sigma s_{c}^{-1} s_{g}\left(\frac{\bar{\tau} \bar{Y}}{\bar{S}}+\frac{\bar{Y}}{\bar{S}}\right) \hat{Y}_{t} \hat{G}_{t}+\sigma s_{c}^{-1} s_{z} \frac{\bar{Y}}{\bar{S}} \hat{Y}_{t} \hat{Z}_{t}+\sigma s_{c}^{-1} s_{g} \frac{\bar{\tau} \bar{Y}}{\bar{S}} \hat{\tau}_{t} \hat{G}_{t}\right] \\
& +\mathcal{O}\left(\left\|\xi_{t}\right\|^{3}\right) \\
= & \bar{U}_{c} \bar{S}\left\{\left(-\frac{\sigma}{s_{c}}+\frac{\bar{\tau} \bar{Y}}{\bar{S}}\right) \hat{Y}_{t}+\frac{\bar{\tau} \bar{Y}}{\bar{S}} \hat{\tau}_{t}+\frac{1}{2} \frac{\bar{\tau} \bar{Y}}{\bar{S}} \hat{\tau}_{t}^{2}+\frac{1}{2}\left[\frac{\bar{\tau} \bar{Y}}{\bar{S}}\left(1-\frac{2 \sigma}{s_{c}}\right)-\frac{\sigma}{s_{c}}+\frac{\sigma^{2}}{s_{c}^{2}}+\frac{\sigma}{s_{c}^{2}}\right] \hat{Y}_{t}^{2}+\frac{\bar{\tau} \bar{Y}}{\bar{S}}\left(1-\sigma s_{c}^{-1}\right) \hat{Y}_{t} \hat{\tau}_{t}\right. \\
& \left.+\sigma \frac{s_{g}}{s_{c}} \frac{\bar{\tau} \bar{Y}}{\bar{S}} \hat{G}_{t} \hat{\tau}_{t}+\sigma \frac{s_{z}}{s_{c}} \frac{\bar{Y} \bar{S}}{\hat{Y}_{t}} \hat{Z}_{t}-\sigma \frac{s_{g}}{s_{c}}\left(\frac{\sigma+1}{s_{c}}-\frac{\bar{\tau} \bar{Y}}{\bar{S}}-\frac{\bar{Y}}{\bar{S}}\right) \hat{Y}_{t} \hat{G}_{t}-\frac{\bar{Z}}{\bar{S}} \hat{Z}_{t}+\left(\sigma s_{c}^{-1} s_{g}-\frac{\bar{G}}{\bar{S}}\right) \hat{G}_{t}\right\}+\mathcal{O}\left(\left\|\xi_{t}\right\|^{3}\right)
\end{aligned}
$$

Therefore, by substituting (D.9) into (D.5), we express the second-order approximation to government $\mathrm{lEC}$ as

$$
\begin{aligned}
\frac{W_{0}-\bar{W}}{\bar{W}}= & (1-\beta) E_{0} \sum_{t=0}^{\infty} \beta^{t}\left[\left\{B_{y} \hat{Y}_{t}+B_{\tau} \hat{\tau}_{t}+B_{y \tau} \hat{Y}_{t} \hat{\tau}_{t}+\frac{1}{2} B_{y y} \hat{Y}_{t}^{2}+\frac{1}{2} B_{\tau \tau} \hat{\tau}_{t}^{2}+B_{\xi_{y}}^{\prime} \hat{\xi}_{t} \hat{Y}_{t}+B_{\xi_{\tau}}^{\prime} \hat{\xi}_{t} \hat{\tau}_{t}+B_{\xi}^{\prime} \hat{\xi}_{t}\right\}\right. \\
& +\mathcal{O}\left(\left\|\xi_{t}\right\|^{3}\right)+\text { t.i.p. }
\end{aligned}
$$


where

$$
\begin{array}{lrl}
B_{y}=-\frac{\sigma}{s_{c}}+\frac{\bar{\tau} \bar{Y}}{\bar{S}} & B_{\tau}=\frac{\bar{\tau} \bar{Y}}{\bar{S}} & B_{\xi}^{\prime} \hat{\xi}_{t}=-\frac{s_{z}}{s_{d}} \hat{Z}_{t}+\left(\sigma \frac{s_{c}}{s_{g}}-\frac{s_{g}}{s_{d}}\right) \hat{G}_{t} \\
B_{y \tau}=\frac{\bar{\tau} \bar{Y}}{\bar{S}}\left(1-\sigma s_{c}^{-1}\right) & B_{y y}=\frac{\bar{\tau} \bar{Y}}{\bar{S}}\left(1-\frac{2 \sigma}{s_{c}}\right)-\frac{\sigma}{s_{c}}+\frac{\sigma^{2}}{s_{c}^{2}}+\frac{\sigma}{s_{c}^{2}} \\
B_{\xi_{y}}^{\prime} \hat{\xi}_{t}=\sigma \frac{s_{z}}{s_{c}} \frac{1}{s_{d}} \hat{Z}_{t}-\sigma \frac{s_{g}}{s_{c}}\left(\frac{\sigma+1}{s_{c}}-\frac{\bar{\tau} \bar{Y}}{\bar{S}}-\frac{1}{s_{d}}\right) \hat{G}_{t} & B_{\xi_{\tau}}^{\prime} \hat{\xi}_{t}=\sigma \frac{s_{g}}{s_{c}} \frac{\bar{\tau} \bar{Y}}{\bar{S}} \hat{G}_{t}
\end{array}
$$

$s_{z}=\frac{\bar{Z}}{\bar{Y}}$ is steady state government transfer payment to GDP ratio; $s_{d}=\frac{\bar{S}}{\bar{Y}}$ is steady state surplus to GDP ratio.

\section{E Second-Order Approximation to Aggregate Supply Relation} The aggregate supply relation is defined by the equations

$$
\begin{aligned}
& J_{t}\left[\frac{1-\theta \pi_{t}^{\epsilon-1}}{1-\theta}\right]^{\frac{1+\epsilon \varphi}{1-\epsilon}}=\frac{\epsilon}{\epsilon-1} K_{t} \\
& K_{t}=\mu_{t}^{W}\left(\frac{Y_{t}}{A_{t}}\right)^{\varphi+1}+\beta \theta E_{t} K_{t+1} \pi_{t+1}^{\epsilon(1+\varphi)} \\
& J_{t}=\left(1-\tau_{t}\right) U_{c, t} Y_{t}+\beta \theta E_{t} J_{t+1} \pi_{t+1}^{\epsilon-1}
\end{aligned}
$$

A second-order approximation to (E.1) can be written as

$$
\frac{\epsilon}{\epsilon-1} \tilde{K}_{t}-\tilde{J}_{t}=\bar{J} \frac{\theta}{1-\theta}(1+\epsilon \varphi)\left\{\tilde{\pi}_{t}+\frac{1}{2}\left[\frac{\theta}{1-\theta} \epsilon(\varphi+1)+(\epsilon-2)\right] \tilde{\pi}_{t}^{2}\right\}+\frac{\theta}{1-\theta}(1+\epsilon \varphi) \tilde{J}_{t} \tilde{\pi}_{t}+\mathcal{O}\left(\left\|\xi_{t}\right\|^{3}\right)
$$

A second-order approximation to (E.2) can be written as

$$
\begin{aligned}
\tilde{K}_{t}= & \beta \theta E_{t} \tilde{K}_{t+1}+\beta \theta \epsilon(1+\varphi) \bar{K}\left\{E_{t} \tilde{\pi}_{t+1}+\frac{1}{2}[\epsilon(1+\varphi)-1] E_{t} \tilde{\pi}_{t+1}^{2}\right\}+\beta \theta \epsilon(1+\varphi) \tilde{K}_{t+1} \tilde{\pi}_{t+1} \\
& +\bar{\mu}^{W}(1+\varphi) \bar{Y}^{\varphi} \tilde{Y}_{t}-\bar{\mu}^{W}(1+\varphi)^{2} \bar{Y}^{\varphi} \tilde{Y}_{t} \tilde{A}_{t}+(\varphi+1) \bar{Y}^{\varphi} \tilde{\mu}_{t}^{W} \tilde{Y}_{t}+\frac{1}{2} \bar{\mu}^{W} \varphi(1+\varphi) \bar{Y}^{\varphi-1} \tilde{Y}_{t}^{2} \\
& -\bar{\mu}^{W}(\varphi+1) \bar{Y}^{\varphi+1} \tilde{A}_{t}+\bar{Y}^{\varphi+1} \tilde{\mu}_{t}^{W}+\mathcal{O}\left(\left\|\xi_{t}\right\|^{3}\right)+\text { t.i.p. }
\end{aligned}
$$

A second-order approximation to (E.3) can be written as

$$
\begin{aligned}
\tilde{J}_{t}= & \beta \theta E_{t} \tilde{J}_{t+1}+\beta \theta(\epsilon-1) \bar{J}\left[E_{t} \tilde{\pi}_{t+1}+\frac{1}{2}(\epsilon-2) E_{t} \tilde{\pi}_{t+1}^{2}\right]+\beta \theta(\epsilon-1) \tilde{J}_{t+1} \tilde{\pi}_{t+1} \\
& +(1-\bar{\tau})\left(\bar{U}_{c}+\bar{U}_{c c} \bar{Y}\right) \tilde{Y}_{t}-\bar{U}_{c} \bar{Y} \tilde{\tau}_{t}+\frac{1}{2}(1-\bar{\tau})\left(2 \bar{U}_{c c}+\bar{U}_{c c c} \bar{Y}\right) \tilde{Y}_{t}^{2}-\left(\bar{U}_{c}+\bar{U}_{c c} \bar{Y}\right) \tilde{Y}_{t} \tilde{\tau}_{t} \\
& +\bar{U}_{c c} \bar{Y} \tilde{\tau}_{t} \tilde{G}_{t}-(1-\bar{\tau})\left(\bar{U}_{c c}+\bar{U}_{c c c} \bar{Y}\right) \tilde{Y}_{t} \tilde{G}_{t}-(1-\bar{\tau}) \bar{Y} \bar{U}_{c c} \tilde{G}_{t}+\mathcal{O}\left(\left\|\xi_{t}\right\|^{3}\right)+t . i . p .
\end{aligned}
$$


Therefore, $\frac{\epsilon}{\epsilon-1}($ E.5)-(E.6) can be expressed as

$$
\begin{aligned}
\frac{\epsilon}{\epsilon-1} \tilde{K}_{t}-\tilde{J}_{t}= & \beta \theta E_{t}\left(\frac{\epsilon}{\epsilon-1} \tilde{K}_{t+1}-\tilde{J}_{t+1}\right) \\
& +\frac{\epsilon}{\epsilon-1} \beta \theta \epsilon(1+\varphi) \bar{K}\left\{E_{t} \tilde{\pi}_{t+1}+\frac{1}{2}[\epsilon(1+\varphi)-1] E_{t} \tilde{\pi}_{t+1}^{2}\right\}-\beta \theta(\epsilon-1) \bar{J}\left[E_{t} \tilde{\pi}_{t+1}+\frac{1}{2}(\epsilon-2) E_{t} \tilde{\pi}_{t+1}^{2}\right] \\
& +\frac{\epsilon}{\epsilon-1} \beta \theta \epsilon(1+\varphi) \tilde{K}_{t+1} \tilde{\pi}_{t+1}-\beta \theta(\epsilon-1) \tilde{J}_{t+1} \tilde{\pi}_{t+1} \\
& +\frac{\epsilon}{\epsilon-1}\left[\bar{\mu}^{W}(1+\varphi) \bar{Y}^{\varphi} \tilde{Y}_{t}-\bar{\mu}^{W}(1+\varphi)^{2} \bar{Y}^{\varphi} \tilde{Y}_{t} \tilde{A}_{t}+(\varphi+1) \bar{Y}^{\varphi} \tilde{\mu}_{t}^{W} \tilde{Y}_{t}+\frac{1}{2} \bar{\mu}^{W} \varphi(1+\varphi) \bar{Y}^{\varphi-1} \tilde{Y}_{t}^{2}\right. \\
& \left.-\bar{\mu}^{W}(\varphi+1) \bar{Y}^{\varphi+1} \tilde{A}_{t}+\bar{Y}^{\varphi+1} \tilde{\mu}_{t}^{W}\right] \\
& -\left[(1-\bar{\tau})\left(\bar{U}_{c}+\bar{U}_{c c} \bar{Y}\right) \tilde{Y}_{t}-\bar{U}_{c} \bar{Y} \tilde{\tau}_{t}+\frac{1}{2}(1-\bar{\tau})\left(2 \bar{U}_{c c}+\bar{U}_{c c c} \bar{Y}\right) \tilde{Y}_{t}^{2}-\left(\bar{U}_{c}+\bar{U}_{c c} \bar{Y}\right) \tilde{Y}_{t} \tilde{\tau}_{t}\right] \\
& -\left[\bar{U}_{c c} \bar{Y} \tilde{\tau}_{t} \tilde{G}_{t}-(1-\bar{\tau})\left(\bar{U}_{c c}+\bar{U}_{c c c} \bar{Y}\right) \tilde{Y}_{t} \tilde{G}_{t}-(1-\bar{\tau}) \bar{Y} \bar{U}_{c c} \tilde{G}_{t}\right]+\mathcal{O}\left(\left\|\xi_{t}\right\|^{3}\right)+t . i . p . \quad(\mathrm{E} .7)
\end{aligned}
$$

Then we plug (E.4) into (E.7) and obtain

$$
\begin{aligned}
& \bar{J} \frac{\theta}{1-\theta}(1+\epsilon \varphi)\left\{\tilde{\pi}_{t}+\frac{1}{2}\left[\frac{\theta}{1-\theta} \epsilon(\varphi+1)+(\epsilon-2)\right] \tilde{\pi}_{t}^{2}\right\}+\frac{\theta}{1-\theta}(1+\epsilon \varphi) \tilde{J}_{t} \tilde{\pi}_{t} \\
= & \beta \theta \bar{J} \frac{\theta}{1-\theta}(1+\epsilon \varphi)\left\{E_{t} \tilde{\pi}_{t+1}+\frac{1}{2}\left[\frac{\theta}{1-\theta} \epsilon(\varphi+1)+(\epsilon-2)\right] E_{t} \tilde{\pi}_{t+1}^{2}\right\}+\beta \theta \frac{\theta}{1-\theta}(1+\epsilon \varphi) \tilde{J}_{t+1} \tilde{\pi}_{t+1} \\
& +\frac{\epsilon}{\epsilon-1} \beta \theta \epsilon(1+\varphi) \bar{K}\left\{E_{t} \tilde{\pi}_{t+1}+\frac{1}{2}[\epsilon(1+\varphi)-1] E_{t} \tilde{\pi}_{t+1}^{2}\right\}-\beta \theta(\epsilon-1) \bar{J}\left[E_{t} \tilde{\pi}_{t+1}+\frac{1}{2}(\epsilon-2) E_{t} \tilde{\pi}_{t+1}^{2}\right] \\
& +\beta \theta \epsilon(1+\varphi)\left[\tilde{J}_{t+1} \tilde{\pi}_{t+1}+\bar{J} \frac{\theta}{1-\theta}(1+\epsilon \varphi) \tilde{\pi}_{t+1}^{2}\right]-\beta \theta(\epsilon-1) \tilde{J}_{t+1} \tilde{\pi}_{t+1} \\
& +\frac{\epsilon}{\epsilon-1}\left[\bar{\mu}^{W}(1+\varphi) \bar{Y}^{\varphi} \tilde{Y}_{t}-\bar{\mu}^{W}(1+\varphi)^{2} \bar{Y}^{\varphi} \tilde{Y}_{t} \tilde{A}_{t}+(\varphi+1) \bar{Y}^{\varphi} \tilde{\mu}_{t}^{W} \tilde{Y}_{t}+\frac{1}{2} \bar{\mu}^{W} \varphi(1+\varphi) \bar{Y}^{\varphi-1} \tilde{Y}_{t}^{2}\right. \\
& \left.-\bar{\mu}^{W}(\varphi+1) \bar{Y}^{\varphi+1} \tilde{A}_{t}+\bar{Y}^{\varphi+1} \tilde{\mu}_{t}^{W}\right] \\
& -\left[(1-\bar{\tau})\left(\bar{U}_{c}+\bar{U}_{c c} \bar{Y}\right) \tilde{Y}_{t}-\bar{U}_{c} \bar{Y} \tilde{\tau}_{t}+\frac{1}{2}(1-\bar{\tau})\left(2 \bar{U}_{c c}+\bar{U}_{c c c} \bar{Y}\right) \tilde{Y}_{t}^{2}-\left(\bar{U}_{c}+\bar{U}_{c c} \bar{Y}\right) \tilde{Y}_{t} \tilde{\tau}_{t}\right] \\
& -\left[\bar{U}_{c c} \bar{Y} \tilde{\tau}_{t} \tilde{G}_{t}-(1-\bar{\tau})\left(\bar{U}_{c c}+\bar{U}_{c c c} \bar{Y}\right) \tilde{Y}_{t} \tilde{G}_{t}-(1-\bar{\tau}) \bar{Y} \bar{U}_{c c} \tilde{G}_{t}\right]+\mathcal{O}\left(\left\|\xi_{t}\right\|^{3}\right)+t . i . p .
\end{aligned}
$$

Note that at steady state we have the relations $\frac{\bar{K}}{\bar{J}}=\frac{\epsilon-1}{\epsilon},(1-\beta \theta) \bar{K}=\bar{Y}^{\varphi+1}$ and $(1-\beta \theta) \bar{J}=$ $(1-\bar{\tau}) \bar{U}_{c} \bar{Y}$, therefore (E.8) can be simplified as

$$
\begin{aligned}
& \frac{\theta}{1-\theta}(1+\epsilon \varphi) \hat{\pi}_{t}+\frac{1}{2} \frac{\theta}{1-\theta}(1+\epsilon \varphi)\left[\frac{\theta}{1-\theta} \epsilon(\varphi+1)+(\epsilon-1)\right] \hat{\pi}_{t}^{2}+\frac{\theta}{1-\theta}(1+\epsilon \varphi) \bar{J}^{-1} \hat{J}_{t} \hat{\pi}_{t} \\
= & \frac{\theta}{1-\theta}(1+\epsilon \varphi) \beta E_{t} \hat{\pi}_{t+1}+\frac{1}{2} \frac{\theta}{1-\theta}(1+\epsilon \varphi) \beta\left[\frac{1}{1-\theta} \epsilon(\varphi+1)+(\epsilon-1)\right] \hat{\pi}_{t+1}^{2}+\beta \frac{\theta}{1-\theta}(1+\epsilon \varphi) \bar{J}^{-1} \hat{J}_{t+1} \hat{\pi}_{t+1} \\
& +(1-\beta \theta)\left[(1+\varphi) \hat{Y}_{t}-(1+\varphi)^{2} \hat{Y}_{t} \hat{A}_{t}+(1+\varphi) \hat{Y}_{t} \hat{\mu}_{t}^{W}+\frac{1}{2}(1+\varphi)^{2} \hat{Y}_{t}^{2}-(1+\varphi) \hat{A}_{t}+\hat{\mu}_{t}^{W}\right] \\
& -(1-\beta \theta)\left\{\left(1-\sigma s_{c}^{-1}\right) \hat{Y}_{t}-w_{\tau} \hat{\tau}_{t}-w_{\tau}\left(1-\sigma s_{c}^{-1}\right) \hat{Y}_{t} \hat{\tau}_{t}-\frac{1}{2} w_{\tau} \hat{\tau}_{t}^{2}+\frac{1}{2}\left[1-3 \sigma s_{c}^{-1}+\sigma(1+\sigma) s_{c}^{-2}\right] \hat{Y}_{t}^{2}\right. \\
& \left.-\sigma \frac{s_{g}}{s_{c}} w_{\tau} \hat{\tau}_{t} \hat{G}_{t}-\left[\sigma(1+\sigma) s_{c}^{-2}-\sigma s_{c}^{-1}\right] s_{g} \hat{Y}_{t} \hat{G}_{t}+\sigma \frac{s_{g}}{s_{c}} \hat{G}_{t}\right\}+\mathcal{O}\left(\left\|\xi_{t}\right\|^{3}\right)+\text { t.i.p. }
\end{aligned}
$$

Define $V_{t}=\hat{\pi}_{t}+\frac{1}{2}\left[\frac{1}{1-\theta} \epsilon(\varphi+1)+(\epsilon-1)\right] \hat{\pi}_{t}^{2}+\bar{J}^{-1} \hat{J}_{t} \hat{\pi}_{t}$, and substitue into (E.9), we obtain a recursive relation

$$
\begin{aligned}
V_{t}= & \left.\kappa\left\{C_{y} \hat{Y}_{t}+C_{\tau} \hat{\tau}_{t}+C_{y \tau} \hat{Y}_{t} \hat{\tau}_{t}+\frac{1}{2} C_{y y} \hat{Y}_{t}^{2}+\frac{1}{2} C_{\tau \tau} \hat{\tau}_{t}^{2}+C_{\xi_{y}}^{\prime} \hat{\xi}_{t} \hat{Y}_{t}+C_{\xi_{\tau}}^{\prime} \hat{\xi}_{t} \hat{\tau}_{t}+\frac{C_{\pi}}{2} \pi_{t}^{2}+C_{\xi}^{\prime} \hat{\xi}_{t}\right\}\right\}+\beta E_{t} V_{t+1} \\
& +\mathcal{O}\left(\left\|\xi_{t}\right\|^{3}\right)+t . i . p .
\end{aligned}
$$


where

$$
\begin{array}{lcc}
C_{y}=1 & C_{\tau}=\psi & C_{\pi}=\frac{\epsilon(1+\varphi)}{\kappa} \\
C_{y \tau}=\left(1-\sigma s_{c}^{-1}\right) \psi & C_{\tau \tau}=\psi & C_{y y}=\left(2+\varphi-\sigma s_{c}^{-1}\right)+\sigma\left(s_{c}^{-1}-s_{c}^{-2}\right)\left(\varphi+\sigma s_{c}^{-1}\right)^{-1} \\
C_{\xi_{y}}^{\prime} \hat{\xi}_{t}=\frac{\sigma^{2} s_{c}^{-2}+\sigma s_{c}^{-2}-\sigma s_{c}^{-1}}{\varphi+\sigma s_{c}^{-1}} s_{g} \hat{G}_{t}-\frac{(1+\varphi)^{2}}{\varphi+\sigma s_{c}^{-1}} \hat{A}_{t}+\frac{1+\varphi}{\varphi+\sigma s_{c}^{-1}} \hat{\mu}_{t}^{W} & C_{\xi_{\tau}}^{\prime} \hat{\xi}_{t}=\sigma s_{c}^{-1} s_{g} \psi \hat{G}_{t} \\
C_{\xi}^{\prime} \hat{\xi}_{t}=-\frac{\varphi+1}{\varphi+\sigma s_{c}^{-1}} \hat{A}_{t}-\frac{s_{g}}{s_{c}} \frac{\sigma}{\varphi+\sigma s_{c}^{-1}} \hat{G}_{t} & \\
\text { and } &
\end{array}
$$

$$
\begin{aligned}
& \kappa=\frac{1-\theta}{\theta} \frac{(1-\beta \theta)\left(\varphi+\sigma s_{c}^{-1}\right)}{1+\epsilon \varphi} \\
& w_{\tau}=\frac{\bar{\tau}}{1-\bar{\tau}} \\
& \psi=\frac{w_{\tau}}{\varphi+\sigma s_{c}^{-1}}
\end{aligned}
$$

Integrate (E.10) forward from $t=0$, we have

$$
\begin{aligned}
V_{0}= & E_{0} \sum_{t=0}^{\infty} \beta^{t} \kappa\left\{C_{y} \hat{Y}_{t}+C_{\tau} \hat{\tau}_{t}+C_{y \tau} \hat{T}_{t} \hat{\tau}_{t}+\frac{1}{2} C_{y y} \hat{Y}_{t}^{2}+\frac{1}{2} C_{\tau \tau} \hat{\tau}_{t}^{2}+C_{\xi_{y}}^{\prime} \hat{\xi}_{t} \hat{Y}_{t}+C_{\xi_{\tau}}^{\prime} \hat{\xi}_{t} \hat{\tau}_{t}+\frac{C_{\pi}}{2} \hat{\pi}_{t}^{2}+C_{\xi}^{\prime} \hat{\xi}_{t}\right\} \\
& +\mathcal{O}\left(\left\|\xi_{t}\right\|^{3}\right)+\text { t.i.p. }
\end{aligned}
$$

\section{F Quadratic Approximation to Objective Function}

Now we use a linear combination of (D.10) and (E.11) to eliminate the linear term in the second order approximation to the welfare measure. The coefficients $\mu_{B}, \mu_{C}$ should satisfy

$$
\begin{aligned}
& \mu_{B} B_{y}+\mu_{C} C_{y}=-\Phi \\
& \mu_{B} B_{\tau}+\mu_{C} C_{\tau}=0
\end{aligned}
$$

The solution is

$$
\begin{aligned}
\mu_{B} & =\frac{\Phi w_{\tau}}{\Gamma} \\
\mu_{C} & =-\frac{\Phi\left(1+w_{g}\right)\left(\varphi+\sigma s_{c}^{-1}\right)}{\Gamma}
\end{aligned}
$$

where $w_{g}=\frac{\bar{G}+\bar{Z}}{S}$ is steady-state government outlays to surplus ratio, and satisfies $1+w_{g}=\frac{\bar{\tau} \bar{Y}}{\bar{S}}$. $\Gamma=\sigma s_{c}^{-1} w_{\tau}+\left(1+w_{g}\right)\left(\varphi+\sigma s_{c}^{-1}-w_{\tau}\right)$.

Therefore, we can finally express the objective function in the linear quadratic form of $\left(\bar{u}_{Y} \bar{Y}\right)^{-1}\left(U_{0}-\bar{U}_{0}\right)+\mu_{B}(1-\beta)^{-1} \frac{W_{0}-\bar{W}}{\bar{W}}+\mu_{C} \kappa^{-1} V_{0}=-E_{0} \sum_{t=0}^{\infty} \beta^{t}\left[\frac{1}{2} q_{Y}\left(\hat{Y}_{t}-\hat{Y}_{t}^{e}\right)^{2}+\frac{1}{2} q_{\pi} \hat{\pi}_{t}^{2}\right]+\mathcal{O}\left(\left\|\xi_{t}\right\|^{3}\right)+$ t.i.p. 
with

$q_{Y}=(1-\Phi)\left(\varphi+\sigma s_{c}^{-1}\right)+\Phi\left(\varphi+\sigma s_{c}^{-1}\right) \frac{\left(1+w_{g}\right)(1+\varphi)}{\Gamma}+\Phi \sigma s_{c}^{-1} \frac{\left(1+w_{g}\right)\left(1+w_{\tau}\right)}{\Gamma}-\Phi \sigma s_{c}^{-2} \frac{\left(1+w_{g}+w_{\tau}\right)}{\Gamma}$

$q_{\pi}=\frac{\Phi\left(1+w_{g}\right) \epsilon(1+\varphi)\left(\varphi+\sigma s_{c}^{-1}\right)}{\kappa \Gamma}+\frac{(1-\Phi) \epsilon\left(\varphi+\sigma s_{c}^{-1}\right)}{\kappa}$

and $\hat{Y}_{t}^{e}$ denotes the efficient level of output, which is exogenous and depends on the vector of exogenous shocks $\xi_{t}$,

$$
\begin{aligned}
\hat{Y}_{t}^{e} & =q_{Y}^{-1}\left(A_{\xi}^{\prime} \hat{\xi}_{t}+\mu_{B} B_{\xi_{y}}^{\prime} \hat{\xi}_{t}+\mu_{C} C_{\xi_{y}}^{\prime} \hat{\xi}_{t}\right) \\
& =q_{A} \hat{A}_{t}+q_{G} \hat{G}_{t}+q_{Z} \hat{Z}_{t}+q_{W} \hat{\mu}_{t}^{W}
\end{aligned}
$$

where

$$
\begin{aligned}
& q_{A}=q_{Y}^{-1}\left[(1-\Phi)(1+\varphi)+\frac{\Phi\left(1+w_{g}\right)(1+\varphi)^{2}}{\Gamma}\right] \\
& q_{G}=q_{Y}^{-1}\left[\sigma \frac{s_{g}}{s_{c}}-\sigma \frac{s_{g}}{s_{c}} \frac{\Phi w_{\tau}}{\Gamma}\left(\frac{\sigma+1}{s_{c}}-\frac{1}{s_{d}}\right)+\sigma \frac{s_{g}}{s_{c}} \frac{\Phi\left(1+w_{g}\right)}{\Gamma}\left(w_{\tau}+1-\frac{\sigma+1}{s_{c}}\right)\right] \\
& q_{Z}=q_{Y}^{-1} \sigma \frac{\Phi w_{\tau}}{\Gamma} \frac{s_{z}}{s_{c}} \frac{1}{s_{d}} \\
& q_{W}=-q_{Y}^{-1} \sigma \frac{\Phi\left(1+w_{g}\right)(1+\varphi)}{\Gamma}
\end{aligned}
$$

\section{G U.S. DATA}

Unless otherwise noted, the following data are from the National Income and Product Accounts Tables released by the Bureau of Economic Analysis. All NIPA data are nominal and in levels.

Consumption, $C$. Total personal consumption expenditures (Table 1.1.5, line 2).

Government spending, $G$. Federal government consumption expenditures and gross investment (Table 1.1.5, line 22).

GDP, $Y . Y=C+G$.

Total tax revenues, $\tau Y$. Federal current tax receipts (Table 3.2, line 2) plus contributions for government social insurance (Table 3.2, line 11) plus Federal income receipts on assets (Table 3.2 , line 12).

Total government transfers, $Z$. Federal current transfer payments (Table 3.2, line 22) minus Federal current transfer receipts (Table 3.2, line 16) plus Federal capital transfers payments (Table 3.2, line 43) minus Federal capital transfer receipts (Table 3.2, line 39) plus Federal subsidies (Table 3.2 , line 32$)$.

Federal government debt, $Q^{M} B^{M}$. Market value of privately held gross Federal debt, Federal Reserve Bank of Dallas, http://www.dallasfed.org/research/econdata/govdebt.cfm.

Total factor productivity, A. Business sector total factor productivity, produced on 03May-2013 by John Fernald/Kuni Natsuki, http://www.frbsf.org/economic-research/total-factorproductivity-tfp/. All published variables are log-differenced and annualized. To be consistent with model with fixed capital, we compute $d A=d Y-($ dhours $+d L Q)$, where dhours and $d L Q$ are business sector hours and labor composition/quality actually used. Given $d A_{t}=400 * \log \left(A_{t}\right)-$ $\log \left(A_{t-1}\right)$, we compute the annualized level of TFP, normalizing $A_{1947 Q 1}=1$. 


\begin{tabular}{l|l}
\hline \hline Variable & Mean \\
$\mathrm{G} / \mathrm{Y}$ & 0.129 \\
$\tau$ & 0.240 \\
$\mathrm{~B} / \mathrm{Y}$ & 0.489
\end{tabular}

We use data from 1948Q1 to 2013Q1 to calibrate the model to U.S. data. For steady states, we use the sample means reported below. For the quarterly calibration, we multiply $B / Y$ by 4. Lump-sum transfers as a share of GDP adjust to satisfy the steady state government budget constraint.

To calibrate the exogenous processes, we apply a Hodrick and Prescott (1997) filter to time series on $G_{t}, \tau_{t}, Z_{t}$, and $A_{t}$ and estimate $\operatorname{AR}(1)$ processes using the cyclical components of the filtered data, denoting those components by $\hat{g}_{t}, \hat{\tau}_{t}, \hat{z}_{t}, \hat{a}_{t}$. Let the $\operatorname{AR}(1)$ be $\hat{x}_{t}=\rho_{x} \hat{x}_{t-1}+\varepsilon_{x t}$ with standard error of estimate $\sigma_{\varepsilon}$. Estimates appear below with standard errors in parentheses.

\begin{tabular}{l|c|c}
\hline \hline Variable, $x$ & $\rho_{x}$ & $\sigma_{\varepsilon}$ \\
$\hat{g}_{t}$ & 0.886 & 0.027 \\
& $(0.029)$ & \\
$\hat{\tau}_{t}$ & 0.782 & 0.029 \\
& $(0.038)$ & \\
$\hat{z}_{t}$ & 0.549 & 0.045 \\
& $(0.051)$ & \\
$\hat{a}_{t}$ & 0.786 & 0.008 \\
& $(0.038)$ &
\end{tabular}

